\title{
The secretome of human dental pulp stem cells protects myoblasts from hypoxia-induced injury via the Wnt/ß-catenin pathway
}

\author{
WEIHUA ZHANG ${ }^{1,2^{*}}$, LIMING YU $^{1,2^{*}}$, XINXIN HAN ${ }^{1,2}$, JIE PAN $^{1,2}$, JIAJIA DENG $^{1,2}$, LUYING ZHU $^{2,3}$, \\ YUN LU ${ }^{1,2}$, WEI HUANG ${ }^{1,2}$, SHANGFENG LIU ${ }^{1,2}$, QIANG LI ${ }^{1,2}$ and YUEHUA LIU ${ }^{1,2}$ \\ ${ }^{1}$ Department of Orthodontics and ${ }^{2}$ Oral Biomedical Engineering Laboratory, Shanghai Stomatological Hospital, \\ Fudan University, Shanghai 200001; ${ }^{3}$ Department of Orthodontics, Xiangya School of Stomatology \\ (Xiangya Stomatological Hospital), Central South University, Changsha, Hunan 410000, P.R. China
}

Received August 18, 2019; Accepted January 29, 2020

DOI: $10.3892 /$ ijmm.2020.4525

\begin{abstract}
Human dental pulp stem cells (hDPSCs) present several advantages, including their ability to be non-invasively harvested without ethical concern. The secretome of hDPSCs can promote the functional recovery of various tissue injuries. However, the protective effects on hypoxia-induced skeletal muscle injury remain to be explored. The present study demonstrated that $\mathrm{C} 2 \mathrm{C} 12$ myoblast coculture with hDPSCs attenuated $\mathrm{CoCl}_{2}$-induced hypoxic injury compared with $\mathrm{C} 2 \mathrm{C} 12$ alone. The hDPSC secretome increased cell viability and differentiation and decreased $\mathrm{G} 2 / \mathrm{M}$ cell cycle arrest under hypoxic conditions. These results were further verified using hDPSC-conditioned medium (hDPSC-CM). The present data revealed that the protective effects of hDPSC-CM depend on the concentration ratio of the CM. In terms of the underlying molecular mechanism, hDPSC-CM activated the Wnt/ $\beta$-catenin pathway, which increased the protein levels of Wnt1, phosphorylated-glycogen synthase kinase-3 $\beta$ and $\beta$-catenin and the mRNA levels of Wnt target genes. By contrast, an inhibitor (XAV939) of Wnt/ $\beta$-catenin diminished the protective effects of hDPSC-CM. Taken together, the findings of the present study demonstrated that the hDPSC secretome alleviated the hypoxia-induced myoblast injury potentially through regulating the $\mathrm{Wnt} / \beta$-catenin pathway. These findings may provide new insight into a therapeutic alternative using the hDPSC secretome in skeletal muscle hypoxia-related diseases.
\end{abstract}

Correspondence to: Professor Yuehua Liu or Mr Qiang Li, Department of Orthodontics, Shanghai Stomatological Hospital, Fudan University, 356 East Beijing Road, Shanghai 200001, P.R. China

E-mail: liuyuehua@fudan.edu.cn

E-mail: lqq401@sina.com

${ }^{*}$ Contributed equally

Key words: human dental pulp stem cells, coculture, conditioned medium, hypoxia, skeletal muscle, Wnt $/ \beta$-catenin

\section{Introduction}

Hypoxia occurs during numerous common phenomena, including embryogenesis, exposure to high-altitude areas, physical exercise and diseases $(1,2)$. Pathological hypoxia can impair skeletal muscle function, a characteristic that it shares with chronic hypoxia-related diseases, such as chronic heart failure (3), chronic obstructive pulmonary disease (4), type 2 diabetes (5) and obstructive sleep apnea syndrome $(6,7)$. Hypoxia leads to continuous muscle contraction, which in turn leads to muscle fatigue and abnormalities in the morphological structure of muscle cells, which inhibits myogenic differentiation (8-10). Moreover, several studies have reported that hypoxia induces the overproduction of reactive oxygen species (ROS) in skeletal muscle. ROS are a powerful initiator of cellular oxidative stress and apoptosis, which in turn contribute to skeletal muscle injury $(11,12)$. Therefore, it is crucial to mitigate hypoxic injury in the repair of damaged muscle fibers, in order to improve muscle function and resistance to fatigue.

$\mathrm{CoCl}_{2}$, the most commonly used hypoxia mimic, substitutes $\mathrm{Fe}^{2+}$ in prolyl hydroxylases to inhibit its hydroxylation, resulting in hypoxia-inducible factor- $1 \alpha$ (HIF-1 $\alpha)$ stabilization (13). Studies have shown that $\mathrm{CoCl}_{2}$-mimicked hypoxia inhibits cell proliferation and differentiation and induces autophagy, apoptosis and myotube atrophy of C2C12 (14-18).

In general, the cornerstone of treatment for muscle dysfunction in hypoxia-related diseases is rehabilitation-based exercises (such as small muscle mass and inspiratory muscle training, optimized nutrition and electrical stimulation) (19-21). In addition, in vitro and in vivo results have demonstrated that certain small-molecule compounds are effective in alleviating hypoxia-induced skeletal muscle damage $(16,22)$. In previous years, mesenchymal stem cell (MSC) therapy has become an alternative treatment in the field of skeletal muscle repair (23-25). MSCs have biological characteristics such as self-renewal, multidirectional directional differentiation potential and low immunogenicity, making them highly attractive in clinical applications for a variety of diseases. Dental pulp stem cells (DPSCs) are excellent candidates for MSC therapy. Compared with other MSC tissue sources, such as bone marrow, adipose tissue and peripheral blood, DPSCs present some favorable advantages, including their convenient, non-invasive 
harvesting, induction of less trauma, and the absence of ethical concerns (26). However, the therapeutic potential of MSCs is highly dependent on their secretome $(27,28)$. The involved mechanism of the MSCs secretome includes immunomodulation, angiogenesis, anti-apoptosis, anti-oxidative stress and anti-inflammatory functions (29). In vitro, cells secrete factors into the supernatant, also referred to as conditioned medium (CM). Several studies have demonstrated that MSC-CM exerts a marked protective effect against skeletal muscle dysfunction (30-32). However, the potential protective effects of DPSC-CM against hypoxia-induced skeletal muscle injury and the underlying mechanisms remain unclear. In the present study, human DPSCs were used and their CM was co-cultured with murine $\mathrm{C} 2 \mathrm{C} 12$ myoblasts rather than human skeletal muscle cells. Mouse cells are considered as the starting point for investigating the effects of DPSCs and their CM, which will subsequently be injected into mice to verify their efficacy in vivo in a future study, and finally into human subjects. The mouse cells mirror the biology of human cells well in various aspects (33). Previous studies (34-36) have also demonstrated that human cells and/or their $\mathrm{CM}$ have protective effects in mouse and rat cells. Therefore, $\mathrm{C} 2 \mathrm{C} 12$ cells were used in the present study.

$\mathrm{Wnt} / \beta$-catenin signaling plays an important role in satellite cell self-renewal, myoblast proliferation, fusion and myofiber homeostasis in skeletal muscle (37). Skeletal muscle injury initiates Wnt signaling, thereby activating satellite cells, promoting cell proliferation and differentiation and repairing damaged muscle fibers.

The present study sought to investigate whether the secretome of human (h)DPSCs can alleviate hypoxic injury in $\mathrm{C} 2 \mathrm{C} 12$ myoblasts and determine whether the underlying mechanism is associated with regulation of the $\mathrm{Wnt} / \beta$-catenin signaling pathway.

\section{Materials and methods}

hDPSC isolation and CM preparation. Normal human third molar teeth (free of caries and/or periodontitis) indicated for extraction were collected from adults (patient characteristics are summarized in Table I) at the Shanghai Stomatological Hospital. The Shanghai Stomatological Hospital Ethics Association approved the study (approval no. 2019-003) and all methods were implemented in accordance with relevant regulations. All patients provided written informed consent to participate in the study. Immediately following tooth extraction, the teeth were placed in cold PBS containing 5\% penicillin-streptomycin (Gibco; Thermo Fisher Scientific, Inc.) and sent to the lab within $1 \mathrm{~h}$. The tooth surfaces were washed ten times with PBS and cut on the cementoenamel junction. The pulp was gently separated from the teeth, cut into $1 \mathrm{~mm}^{3}$ pieces and then digested in collagenase type I (Gibco; Thermo Fisher Scientific, Inc.) and dispase (Gibco; Thermo Fisher Scientific, Inc.) for $45 \mathrm{~min}$ to $1 \mathrm{~h}$ at $37^{\circ} \mathrm{C}$ with occasional vortexing. Tissues and cells were cultured in $\alpha$-MEM (Gibco; Thermo Fisher Scientific, Inc.) supplemented with $10 \%$ fetal bovine serum (FBS; Gibco; Thermo Fisher Scientific, Inc.) and $1 \%$ penicillin-streptomycin at $37^{\circ} \mathrm{C}$ in $5 \% \mathrm{CO}_{2}$, and the medium was changed every 3 days. All cells used in the present study had undergone three to five passages.
Table I. Donor information.

\begin{tabular}{llc}
\hline Age, years & Sex & Recruitment date \\
\hline 18 & Male & $30 / 04 / 2018$ \\
25 & Female & $28 / 04 / 2018$ \\
25 & Female & $28 / 04 / 2018$
\end{tabular}

hDPSCs from up to three donors were cultured separately and used to conduct the various assays.

A total of $2 \times 10^{5}$ cells were seeded in $100-\mathrm{mm}$ dishes and, when the hDPSCs had reached $70-80 \%$ confluence, the medium was removed, the cells were washed three times with PBS, and the medium was replaced with $10 \mathrm{ml}$ serum-free DMEM (Gibco; Thermo Fisher Scientific, Inc.). After $48 \mathrm{~h}$, the culture medium was centrifuged at $1,000 \mathrm{x}$ g for $3 \mathrm{~min}$ at room temperature; the supernatant was collected and filtered through a $0.22-\mu \mathrm{m}$ filter; subsequently, the $\mathrm{CM}$ was concentrated 30 -fold using an ultrafiltration unit with a 10-kDa molecular weight cutoff (Ultracel-10 membrane; EMD Millipore). All ultrafiltration units were centrifuged at 4,000 $\mathrm{xg}$ for $25 \mathrm{~min}$ at $4^{\circ} \mathrm{C}$. Each concentrated CM was diluted 2-, 5- and 10-fold, and the unconcentrated medium was 1-fold. The CM was stored at $-80^{\circ} \mathrm{C}$ until further use (Fig. 1A). Serum-free DMEM without hDPSCs was used as control CM, and it was incubated, collected and stored in a similar manner.

Cell culture and treatment. The murine myoblast cell line $\mathrm{C} 2 \mathrm{C} 12$ was cultured in DMEM with $10 \%$ FBS and $1 \%$ penicillin-streptomycin (growth medium, GM) at $37^{\circ} \mathrm{C}$ in $5 \% \mathrm{CO}_{2}$, and the medium was changed every 2 days. To introduce myogenic differentiation, the myoblasts were transferred at $90 \%$ confluence to DMEM supplemented with $2 \%$ horse serum (Gibco; Thermo Fisher Scientific, Inc.) and $1 \%$ penicillin-streptomycin (differentiation medium, DM), which was replenished every other day. Hypoxia was induced in $\mathrm{C} 2 \mathrm{C} 12$ cells by employing the widely used hypoxia mimic $200 \mu \mathrm{M} \mathrm{CoCl}_{2}$ (Sigma-Aldrich; Merck KGaA), as detailed in the manufacturer's protocol. $\mathrm{C} 2 \mathrm{C} 12$ myoblasts were treated as follows: Normoxia ( $\mathrm{N}$, control medium), hypoxia $\left(\mathrm{H}, \mathrm{CoCl}_{2}\right.$ treatment with control medium), normoxia + $\mathrm{CM}(\mathrm{N}+\mathrm{CM})$, and hypoxia $+\mathrm{CM}\left(\mathrm{H}+\mathrm{CM}, \mathrm{CoCl}_{2}\right.$ treatment with $\left.\mathrm{CM}\right)$.

hDPSCs-C2C12 coculture system. In a typical experimental coculture system, as illustrated in Fig. 1A, 2.5x10 ${ }^{3} \mathrm{C} 2 \mathrm{C} 12$ cells/well were seeded in 6-well plates and Transwell-Clear inserts $\left(3-\mu \mathrm{m}\right.$ pore size; Corning, Inc.) covered with $5 \times 10^{3}$ hDPSCs/well were placed in another well. After $24 \mathrm{~h}$ of cell attachment, the Transwell was assembled with hDPSCs and wells containing $\mathrm{C} 2 \mathrm{C} 12$. For $\mathrm{C} 2 \mathrm{C} 12$ differentiation, $\mathrm{C} 2 \mathrm{C} 12$ cells were first seeded in 6-well plates at a density of $4 \times 10^{5}$ cells/well in GM, and when the $\mathrm{C} 2 \mathrm{C} 12$ cells reached $90 \%$ confluence, the GM was replaced with DM for 2 days to initiate differentiation. The hDPSCs-C2C12 cells were further incubated for 2,4 and 6 days in the same coculture experiments. The hDPSCs-C2C12 cells were treated as follows: Normoxia group $(\mathrm{N})$, hypoxia group $(\mathrm{H})$, normoxia + coculture group $(\mathrm{N}+\mathrm{Co})$ and hypoxia + coculture group $(\mathrm{H}+\mathrm{Co})$. 
A
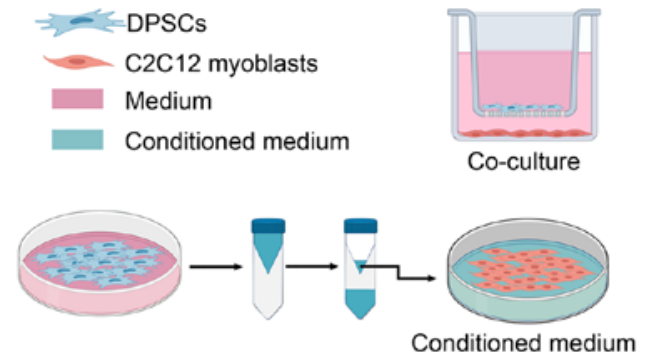

B

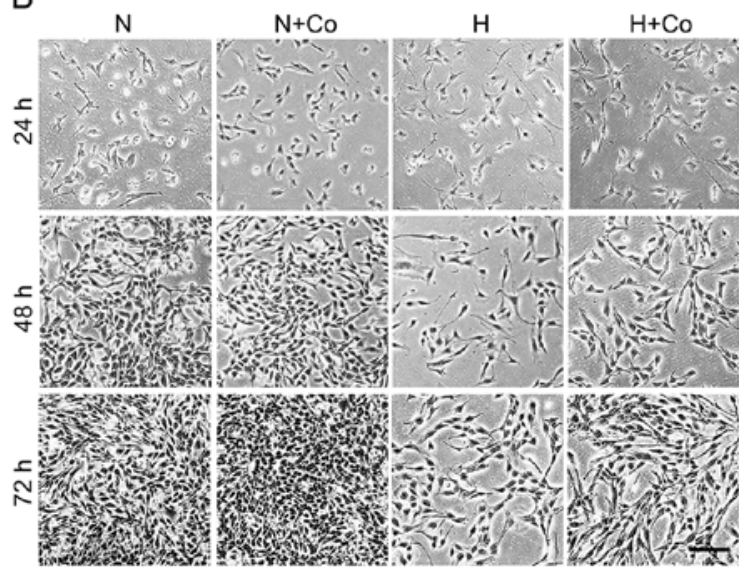

D
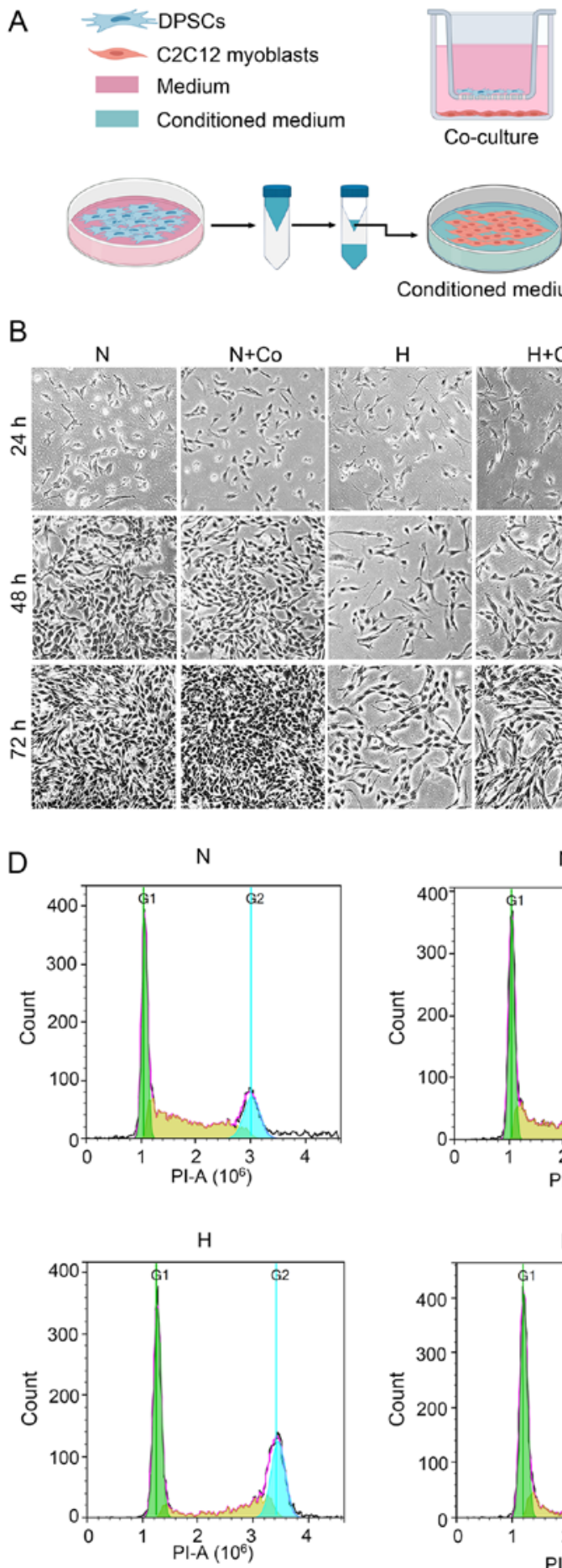

C
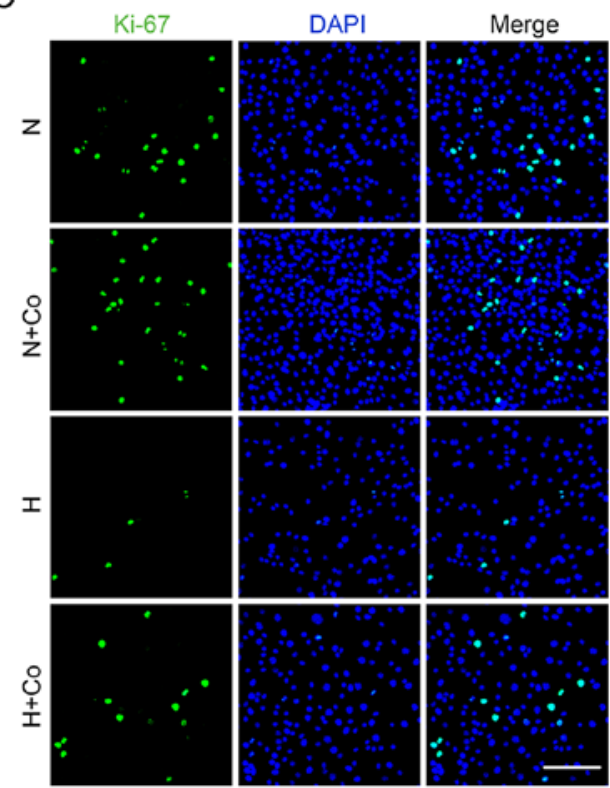

E

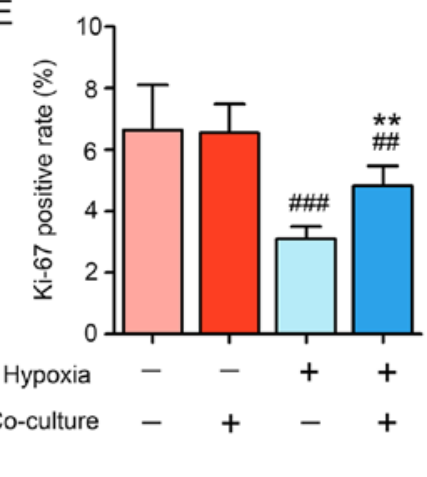

$\mathrm{F}$
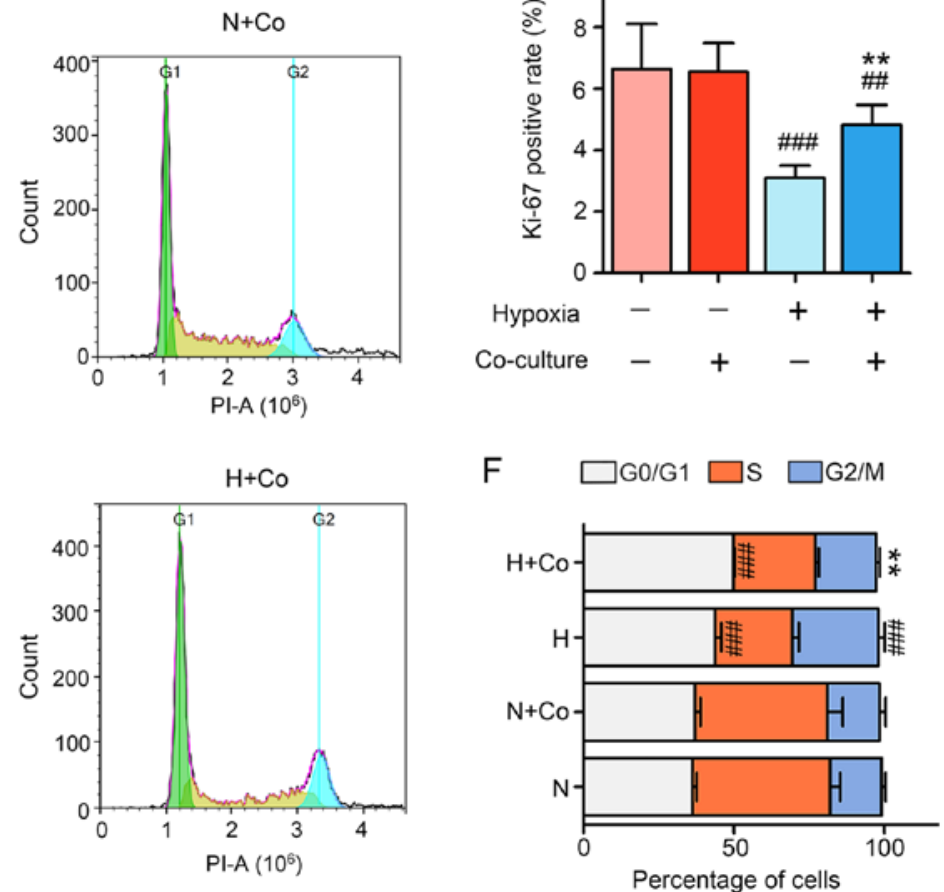

Figure 1. hDPSCs alleviate hypoxia-induced injury of $\mathrm{C} 2 \mathrm{C} 12$ myoblasts in the coculture model. (A) Establishing the hDPSCs-C2C12 coculture system and preparing the hDPSC-CM. Upper: The indirect coculture system with hDPSCs and C2C12 myoblasts was established. C2C12 and cultured hDPSCs were seeded in 6-well plates and Transwell-Clear inserts, respectively, to study the paracrine effects. Lower: The hDPSC growth medium was replaced with serum-free medium, after which time it was collected and concentrated using an ultrafiltration unit $(48 \mathrm{~h})$ and then added to regular medium after diluting to different concentrations. (B) Optical micrographs of $\mathrm{C} 2 \mathrm{C} 12$ cell morphology and quantity change at 24-72 h. Scale bar, $200 \mu \mathrm{m}$. (C) Cell proliferation was assessed through Ki-67 immunofluorescence staining and (E) statistical analysis of the Ki-67 (green)-positive rate. Scale bar, $100 \mu \mathrm{m}$. (D) Cell cycle distribution was monitored using flow cytometry. (F) Statistical analysis of the cell cycle in $\mathrm{C} 2 \mathrm{C} 12$ myoblasts. ${ }^{\# \#} \mathrm{P}<0.01$ and ${ }^{\# \# \#} \mathrm{P}<0.001$ vs. N, ${ }^{* * *} \mathrm{P}<0.01$ vs. H. hDPSCs, human dental pulp stem cells; DAPI, 4',6-diamidino-2-phenylindole; PI, propidium iodide; N, normoxia; H, hypoxia; Co, coculture.

Flow cytometry. After treatment for $24 \mathrm{~h}$, the cells were harvested and centrifuged at 1,500 x g for $3 \mathrm{~min}$ at room temperature, and the supernatant was discarded. The cells were fixed in $70 \%$ precooled ethanol overnight at $4^{\circ} \mathrm{C}$. The next day, the cells were centrifuged at 1,500 $\mathrm{x} g$ for $3 \mathrm{~min}$ at room temperature and washed thrice with PBS. RNase-containing PI solution (BioTime) was then added, and the cells were incubated for $30 \mathrm{~min}$ at $37^{\circ} \mathrm{C}$. Finally, cell cycle analysis was performed using flow cytometry (ACEA NovoCyte) with NovoExpress software version 1.4.1 (ACEA NovoCyte) within $24 \mathrm{~h}$. 
Table II. Sequence of primers used for PCR amplification.

\begin{tabular}{lll}
\hline Gene & \multicolumn{1}{c}{ Forward (5'-3') } & \multicolumn{1}{c}{ Reverse (5'-3') } \\
\hline $18 \mathrm{~s}$ & GTAACCCGTTGAACCCCATT & CCATCCAATCGGTAGTAGCG \\
Myogenin & GAGACATCCCCCTATTTCTACCA & GCTCAGTCCGCTCATAGCC \\
MHC & GCGAATCGAGGCTCAGAACAA & GTAGTTCCGCCTTCGGTCTTG \\
Ccna2 & AGAAGCTCAAGACTCGACGG & AATGGTGAAGGCAGGCTGTT \\
Ccnd1 & GCGTACCCTGACACCAATCTC & ACTTGAAGTAAGATACGGAGGGC \\
Tcf7 & CCCTCAATGCGTTCATGCTTT & CTTGCGGGCCAGTTCATAGT \\
Lef1 & GCCACCGATGAGATGATCCC & TTGATGTCGGCTAAGTCGCC
\end{tabular}

Lef1, lymphoid enhancer binding factor 1; Tcf7, transcription factor 7; Ccnd1, cyclin D1; Ccna2, cyclin A2; MHC, myosin heavy chain.

RNA extraction and gene expression analysis using quantitative PCR. Total RNA was extracted using TRIzol reagent (Thermo Fisher Scientific, Inc.) after different treatments in each group. A total of $1 \mu \mathrm{g}$ extracted RNA was reverse-transcribed into cDNA using a FastQuant RT kit (Tiangen Biotech Co., Ltd.) at $42^{\circ} \mathrm{C}$ for $15 \mathrm{~min}$ and at $95^{\circ} \mathrm{C}$ for 3 min. SuperReal PreMix (Tiangen Biotech Co., Ltd.) was used for amplification of cDNA to the relative mRNA of genes in $10 \mu \mathrm{l}$ of the final volume using a Real-Time PCR System (Biometra Biomedizinische Analytik $\mathrm{GmbH}$ ). The thermocycling conditions were as follows: $95^{\circ} \mathrm{C}$ for $15 \mathrm{~min}$, followed by 40 cycles at $95^{\circ} \mathrm{C}$ for $10 \mathrm{sec}$ and at $60^{\circ} \mathrm{C}$ for $32 \mathrm{sec}$. The results were normalized against the housekeeping gene $18 \mathrm{~S}$. The forwards and reverse primers used are listed in Table II. The relative mRNA expression was calculated by using $2^{-\Delta \Delta \mathrm{Cq}}$ method (38).

Western blotting. Cultured cells were lysed in RIPA buffer (Santa Cruz Biotechnology, Inc.) with protease and phosphatase inhibitors. Protein concentration was determined by the BCA Protein Assay kit (Thermo Fisher Scientific, Inc). Subsequently, total protein samples were prepared using $2 \mathrm{X}$ SDS loading buffer and equal amounts of protein $(30 \mu \mathrm{g})$ were denatured by boiling for $10 \mathrm{~min}$. These samples were loaded into a 10\% SDS-PAGE gel and transferred onto PVDF membranes (EMD Millipore). Ponceau (P0012; Beijing Solarbio Science $\&$ Technology Co., Ltd.)-stained membranes were used for detection of total protein. The membranes were blocked in $5 \%$ non-fat milk diluted in TBS at room temperature for $1 \mathrm{~h}$, and then incubated overnight at $4^{\circ} \mathrm{C}$ with the following primary antibodies: Rabbit anti- $\beta$-catenin (1:1,000, cat. no. 8480; Cell Signaling Technology, Inc.), mouse anti- $\beta$-actin (1:5,000, cat. no. abs830031; Absin Bioscience Inc.), mouse anti-myosin heavy chain (MHC; 1:60, cat. no. MF20; Developmental Studies Hybridoma Bank), mouse anti-myogenin (cat. no. sc-52903), mouse anti-MyoD (cat. no. sc-32758), mouse anti-Wnt1 (cat. no. sc-5630), mouse anti-Wnt4 (cat. no. sc-376279), mouse anti-Wnt7a (cat. no. sc-365665), mouse anti-glycogen synthase kinase (GSK)-3 $\beta$ (cat. no. sc-24563), mouse anti-phosphorylated (p)-GSK-3 $\beta$ (cat. no. sc-11757) (all from Santa Cruz Biotechnology, Inc., except where otherwise indicated, and used at 1:1,000) and mouse anti-HIF-1 $\alpha$ (1:500, cat. no. NB100-105; Novus Biologicals). The membranes were washed with TBS-T ( $0.1 \%$ Tween-20 in TBS) four times for 6 min each and then incubated with horseradish peroxidase-conjugated secondary antibodies (1:10,000; cat. no. 7076 for anti-mouse IgG, cat. no. 7074 for anti-rabbit IgG, both from Cell Signaling Technology, Inc.) for $1.5 \mathrm{~h}$ at room temperature. After four washes for 6 min with TBS-T, the blots were visualized using an enhanced chemiluminescent substrate kit (ECL Advance; Thermo Fisher Scientific, Inc.). The bands were detected with Amersham Imager 600 (GE Healthcare) and then quantified using the Image J program version $1.50 \mathrm{i}$ (National Institute of Health).

Immunofluorescence staining. $\mathrm{C} 2 \mathrm{C} 12$ cells were seeded in 24 -well plates at $2 \times 10^{4} /$ well. After treatment, the medium was carefully removed and the cells were washed twice with PBS. The cells were then fixed in precooled $4 \%$ paraformaldehyde for $15 \mathrm{~min}$ at room temperature. Then, the cells were permeabilized in the presence of PBS with $0.25 \%$ Triton X-100 for 15 min and blocked with $5 \%$ BSA at room temperature for $1 \mathrm{~h}$. The cells were incubated overnight at $4^{\circ} \mathrm{C}$ with mouse anti-MHC (1:500; cat. no. MAB4470, R\&D Systems, Inc.), rabbit anti-Ki-67 (1:1,000; cat. no. MA5-14520, Thermo Fisher Scientific, Inc.), or HIF-1 $\alpha$ in $2.5 \%$ BSA. The cells were then washed three times in PBS with $0.1 \%$ Tween-20 (PBST) and stained for $1 \mathrm{~h}$ at room temperature with anti-mouse FITC-conjugated secondary antibody (1:1,000, cat. no. F-2761, Thermo Fisher Scientific, Inc.) in $2.5 \%$ BSA. After washing five times with PBST, the cells were counterstained with 4',6-diamidino-2-phenylindole $(1: 10,000)$ at room temperature for $10 \mathrm{~min}$. The cells were viewed under a fluorescence microscope (Leica Microsystems, Inc.) and assessed for myogenesis by measuring the number of MHC-positive nuclei in the myotubes in 3-5 randomly selected fields to quantify the differentiation index.

Schematic production. The diagrams, including co-culture model and molecular mechanism, were created using the software available at BioRender (https://app.biorender.com/).

Statistical analysis. All data were processed using GraphPad Prism 5 (GraphPad Software, Inc.) and ImageJ software version 1.50i (National Institute of Health), and the measurement data were analyzed as the mean \pm standard deviation using one-way analysis of variance and Tukey's multiple comparison post hoc test with SPSS Statistical 22.0 software 
(IBM, Corp.). $\mathrm{P}<0.05$ was considered to indicate a statistically significant difference. All assays were repeated three times independently.

\section{Results}

hDPSCs exert cytoprotective effects by enhancing C2C12 viability under hypoxic conditions in a coculture model. To investigate whether the secretome of hDPSCs was effective, an indirect coculture system of hDPSCs and $\mathrm{C} 2 \mathrm{C} 12$ was performed (Fig. 1A). After treatment for 24-72 h, hypoxia in the other groups progressively induced a decline in cell viability in a time-dependent manner, compared with the control group. Hypoxia induction caused an increase in the characteristic cellular extensions and surface area in myoblasts, revealing the stressed state of the cells. After $24 \mathrm{~h}$, there was no apparent difference between the groups under the microscope, whereas the number of cells in the hDPSC coculture group was visibly increased compared with that in the hypoxia group after 48-72 h (Fig. 1B). Furthermore, Ki-67 staining revealed that the rate of cell proliferation significantly increased from $3.1 \pm 0.5$ to $4.8 \pm 0.7 \%$ after hDPSC coculture in hypoxic cells (Fig. 1C and E). In addition, the cell cycle distribution indicated that hDPSCs blocked the G2/M phase arrest caused by hypoxia (Fig. 1D and F). Thus, hDPSCs in coculture with $\mathrm{C} 2 \mathrm{C} 12$ were shown to ameliorate hypoxia-related injury of the skeletal muscle myoblasts through paracrine effects.

hDPSC-CM attenuates hypoxia-induced injury of C2C12 myoblasts in a HIF-1 $\alpha$-independent manner. As MSCs secrete protein or growth factors in their medium, whether hDPSC-CM was beneficial to hypoxia-exposed $\mathrm{C} 2 \mathrm{C} 12$ myoblasts was next investigated. In this study, different fold-increases of hDPSC-CM were used for treatment. Compared with the hypoxia group, it was observed that 5-, 8- and 10-fold CM achieved obvious effects after $48 \mathrm{~h}$ (Fig. 2A). Aftercell counting, it was found that, compared with the hypoxia group, there was no significant difference for the use of 2-fold CM, while there were significant differences for the use of 5-, 8- and 10-fold $\mathrm{CM}$. There was no significant difference among the 5-, 8- and 10 -fold CM groups (Fig. 2C). Therefore, 5X hDPSC-CM was selected for the subsequent experiments. The proliferation of cells was also improved in the $\mathrm{H}+\mathrm{CM}$ group compared with that of cells in the hypoxia group (Fig. 2B and E). Furthermore, whether the effect of hDPSC-CM was associated with changes in HIF-1 $\alpha$ was tested. The results demonstrated that hypoxia increased the expression of HIF-1 $\alpha$ in the nucleus, but there was no significant difference in the effect of hDPSC-CM on HIF-1 $\alpha$ compared with that in the $\mathrm{H}$ group (Fig. 2D and F). The results suggested that hDPSC-CM markedly improved the proliferation and viability of $\mathrm{C} 2 \mathrm{C} 12$, but this protective effect appeared to be unrelated to the level of HIF-1 $\alpha$.

hDPSCs improve hypoxia-induced injury of myogenic differentiation in a cell coculture model. To assess whether hDPSCs affected the physiological function of myoblasts, $\mathrm{C} 2 \mathrm{C} 12$ cells were induced to differentiate for 2 days under normoxic conditions followed by hypoxic treatment for 2 , 4 and 6 days. Myogenin and MHC are specific middle and late differentiation markers during the process of myoblast fusion to form myotubes (39). The myotubes stained positive for MHC by immunofluorescence. These results demonstrated that the $\mathrm{H}$ group significantly inhibited $\mathrm{C} 2 \mathrm{C} 12$ differentiation, myotube rupture and atrophy (Fig. 3A). The data demonstrated that the $\mathrm{H}+\mathrm{Co}$ group stimulated the myogenesis of $\mathrm{C} 2 \mathrm{C} 12$ after 2 days, with a 2.8 -fold increase in the index of differentiation compared with the $\mathrm{H}$ group, whereas there were no significant differences observed between the $\mathrm{N}$ and the $\mathrm{N}+\mathrm{Co}$ groups (Fig. 3D). Furthermore, hDPSCs induced an increase in myogenin mRNA expression and relative protein levels that were 1.66- and 3.3-fold higher after 2 days of differentiation, respectively, compared with the $\mathrm{H}$ group (Fig. 3B, E and F). Analysis of the terminal differentiation marker MHC revealed that its mRNA expression and relative protein level were 2.02and 2.7-fold higher, respectively, in the $\mathrm{H}+\mathrm{Co}$ group compared with the $\mathrm{H}$ group (Fig. 3C, E and G). These results suggest that hDPSCs protected myotubes against hypoxia-induced injury by restoring myogenic differentiation and myotube morphology. However, it was also observed that the protective effect of coculture gradually weakened after 4-6 days and was not significantly different with or without hDPSCs. This may be an experimental limitation of coculture in the study, as both $\mathrm{C} 2 \mathrm{C} 12$ and the hDPSCs were subjected to hypoxic conditions over a long period of time. Damaged hDPSCs may lead to an attenuation of protection due to their decreased paracrine function, even though they continue to achieve significant results in the first 2 days of treatment.

hDPSC-CM ameliorates hypoxia-induced injury of myogenic differentiation. Whether hDPSC-CM was beneficial to myogenic differentiation was next investigated. In the present study, different folds of hDPSC-CM were selected for treatment (1-, 2-, 5- and 10-). As shown in Fig. 4A-C, hypoxia decreased the relative expression of myogenic differentiation genes $(\mathrm{MyoD}$, myogenin and MHC) for $48 \mathrm{~h}$, whereas a moderate concentration of hDPSC-CM reversed the inhibition of myogenic differentiation genes under hypoxia, particularly $2 \mathrm{X}$ hDPSC-CM. The protein level of MyoD was inconsistent with mRNA expression. Compared with other groups, the relative protein level of $\mathrm{MyoD}$ in the normoxia group was significantly downregulated (Fig. 4D and F). The authors considered this result to be partly due to the temporal expression pattern during myogenesis. MyoD is an early expressed gene, while myogenin and MHC are expressed in the middle and late stages. Moreover, it was also possible that MyoD is regulated by post-transcriptional modifications (40). However, analysis of myogenin and MHC after $48 \mathrm{~h}$ revealed that their relative protein levels were upregulated in $\mathrm{H}+2 \mathrm{X}$ hDPSC-CM compared with the hypoxia group, but $1 \mathrm{X}, 5 \mathrm{X}$ and 10X hDPSC-CM was not associated with a significant change (Fig. 4E, G and H). These results demonstrated that treatment with hDPSC-CM at a moderate concentration was capable of attenuating the inhibition of myogenic differentiation, thereby protecting cells and myotubes.

hDPSC-CM mediates Wnt/ $\beta$-catenin signaling in hypoxia-treated $C 2 C 12$ myoblasts. Wnt $/ \beta$-catenin signaling has been shown to be involved in hypoxia-induced cell injury $(41,42)$. To further explore the mechanisms of myoblast damage and the potential protective role of hDPSC-CM against hypoxia, the protein levels of total GSK-3 $\beta$, p-GSK- $3 \beta$ 
A
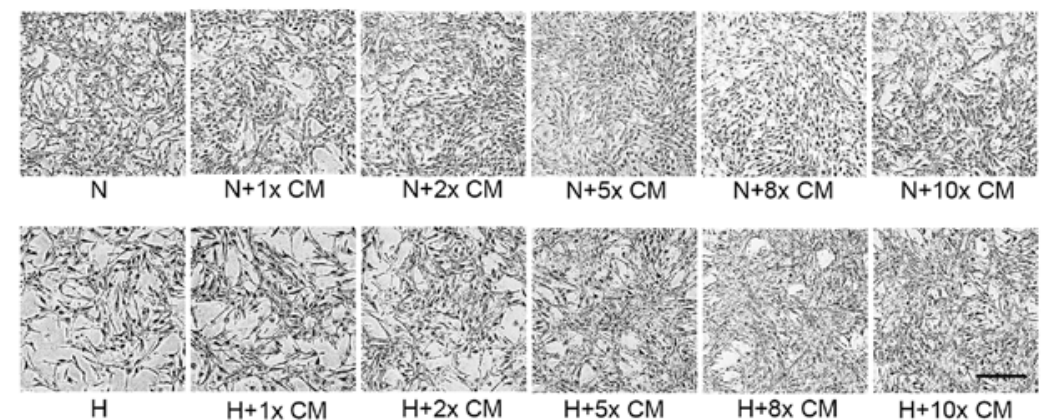

B Ki-67 $\mathrm{H}+1 \times \mathrm{CM}$ $\mathrm{H}+5 \times \mathrm{CM}$ $\mathrm{H}+8 \times \mathrm{CM}$ $\mathrm{H}+10 \times \mathrm{CM}$

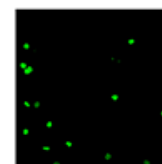

DAPI

Merge
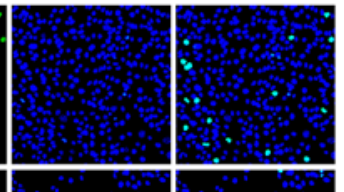

$\mathrm{N}+\mathrm{CM}$
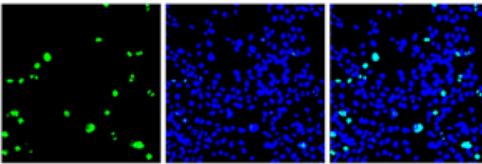

C

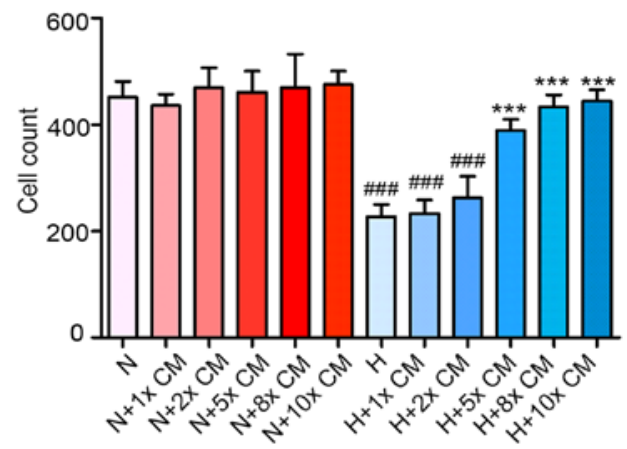

$\mathrm{H}$
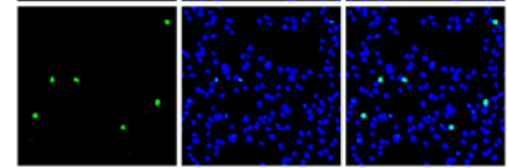

$\mathrm{H}+\mathrm{CM}$
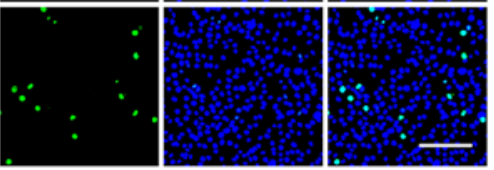

D

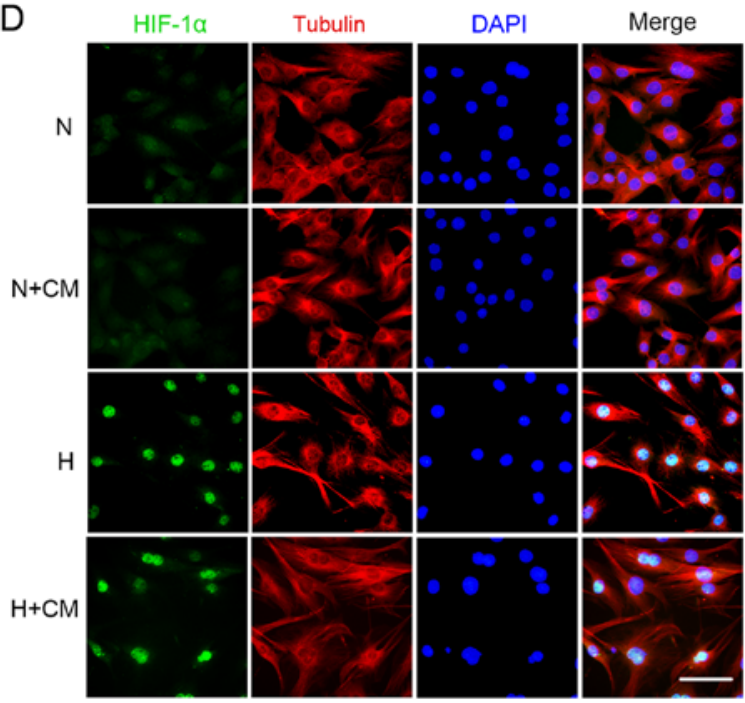

E

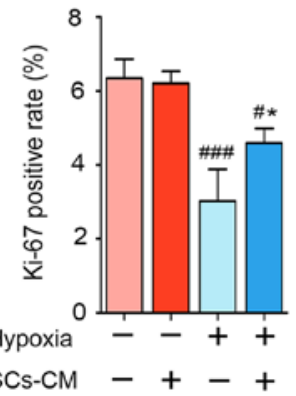

F

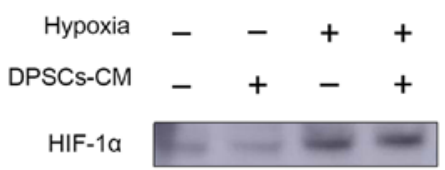

Ponceau

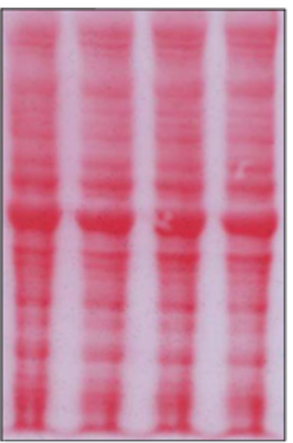

Figure 2. hDPSC-CM improves the hypoxia-induced decrease in the proliferation and viability of C2C12 cells in a HIF-1 $\alpha$-independent manner. (A) Optical micrographs of $\mathrm{C} 2 \mathrm{C} 12$ cell morphology and quantity change for $48 \mathrm{~h}$. Scale bar, $200 \mu \mathrm{m}$. (B) Cell proliferation was assessed through Ki-67 immunofluorescence staining. Scale bar, $100 \mu \mathrm{m}$. (C) The number of cells per field were counted at a magnification of x100. (D) After $24 \mathrm{~h}$ of hypoxia treatment and immunofluorescence staining of HIF-1 $\alpha$ (green) translocation to the nucleus, the cytoplasm was stained with tubulin (red) and the cell nuclei with DAPI (blue). Scale bar, $50 \mu \mathrm{m}$. (E) Cell proliferation was assessed via statistical analysis of the Ki-67-positive rate. (F) Nucleoprotein expression of HIF-1 $\alpha$ was detected using western blotting. " $\mathrm{P}<0.05$ and ${ }^{\# \# \#} \mathrm{P}<0.001$ vs. $\mathrm{N},{ }^{*} \mathrm{P}<0.05$ and ${ }^{* * * *} \mathrm{P}<0.001$ vs. H. HIF, hypoxia inducible factor; hDPSCs, human dental pulp stem cells; CM, conditioned media; N, normoxia; H, hypoxia; DAPI, 4',6-diamidino-2-phenylindole.

(S9) and $\beta$-catenin were detected between 6 and $24 \mathrm{~h}$. As shown in Fig. 5A-C, the relative protein levels of p-GSK-3 $\beta$ (S9) and $\beta$-catenin in the hypoxia group were lower compared with those in the normoxia group for 12 and $24 \mathrm{~h}$, but there were no significant differences at $6 \mathrm{~h}$. In the presence of hDPSC-CM, the $\mathrm{H}+\mathrm{CM}$ group exhibited upregulated levels of p-GSK-3 $\beta$ (S9) and $\beta$-catenin. In addition, hypoxia inhibited the downstream target genes of $\mathrm{Wnt} / \beta$-catenin, including 
A
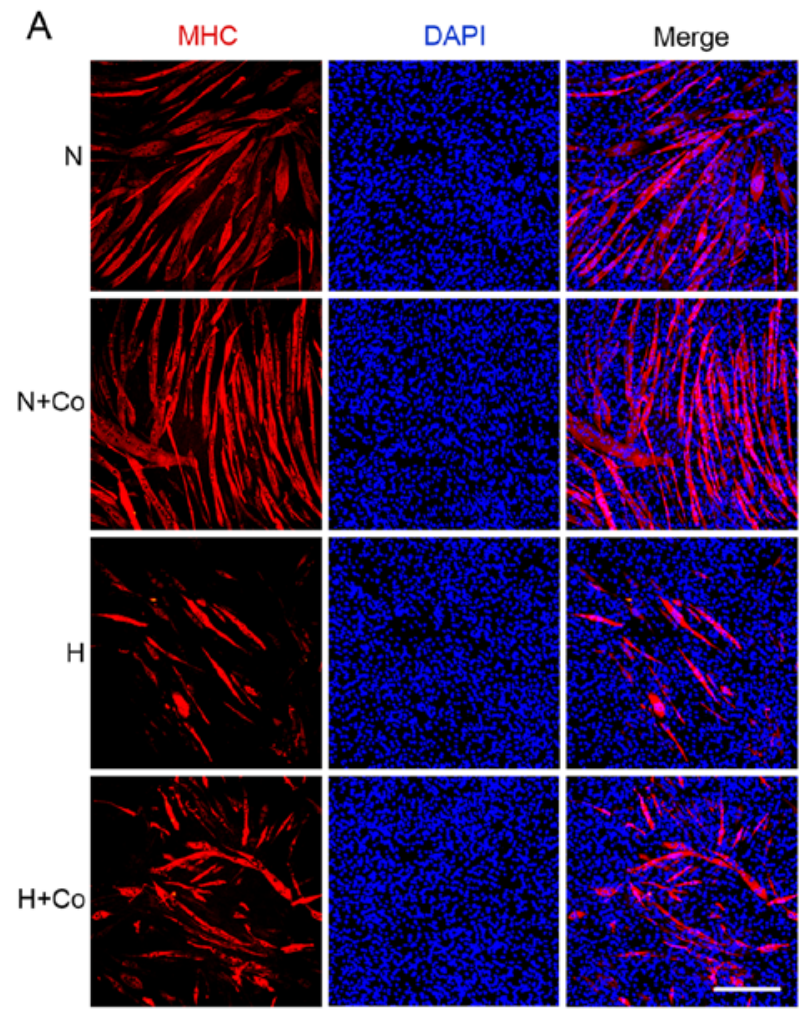

D

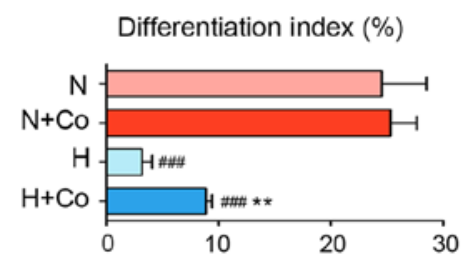

$\mathrm{E}$
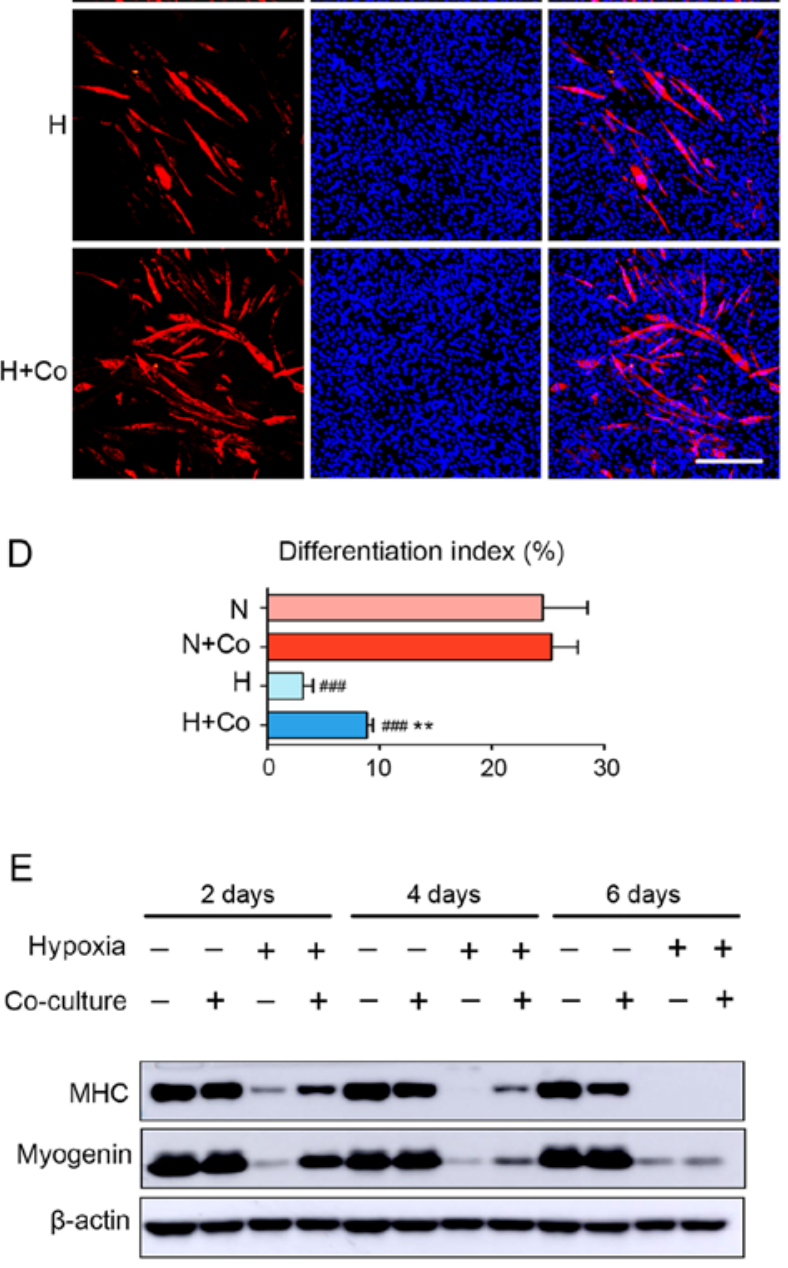

B

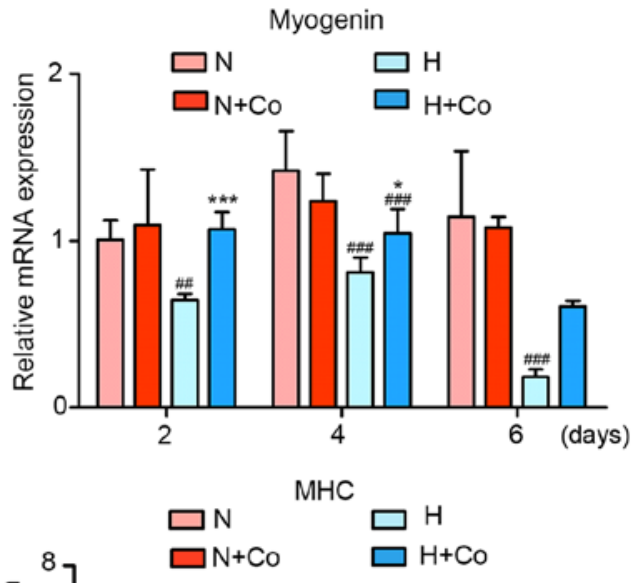

C
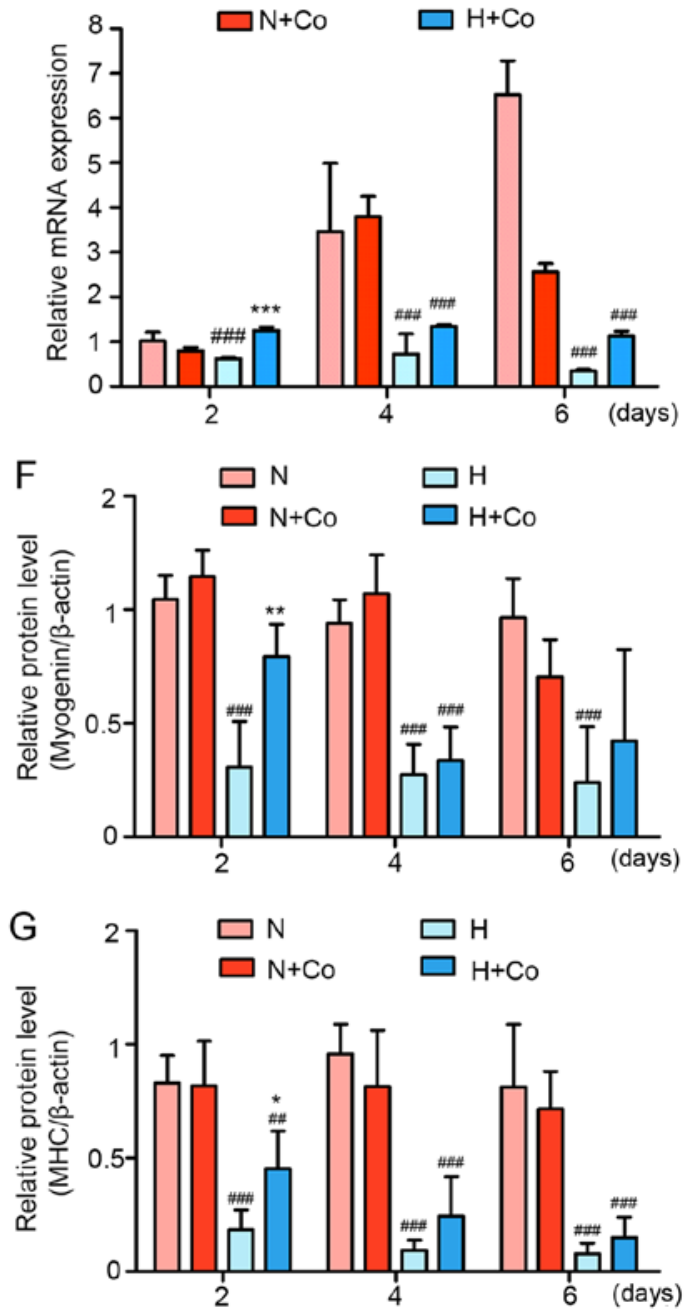

Figure 3. hDPSCs improve hypoxia-induced inhibition of myogenic differentiation in the coculture model. (A) Two days after hypoxia treatment, the formation of myotubes and cell nuclei was assessed using immunofluorescence staining with MHC (red) and DAPI (blue), respectively. Scale bar, $200 \mu \mathrm{m}$. (B and C) The mRNA expression of (B) myogenin and (C) MHC was assessed using quantitative PCR. Data are presented as the fold-change of the normoxia group at 2 days. (D) The differentiation index is presented as the ratio of MHC-positive nuclei to total nuclei. (E) Protein expression of myogenin and MHC was assessed using western blotting. Semiquantitative analysis of the expression ratio of $(\mathrm{F})$ myogenin/ $\beta$-actin and $(\mathrm{G}) \mathrm{MHC} / \beta$-actin. ${ }^{\# \#} \mathrm{P}<0.01$ and ${ }^{\# \# \#} \mathrm{P}<0.001 \mathrm{vs}$. $\mathrm{N}$, ${ }^{*} \mathrm{P}<0.05,{ }^{* *} \mathrm{P}<0.01$ and ${ }^{* * *} \mathrm{P}<0.001$ vs. H. hDPSCs, human dental pulp stem cells; CM, conditioned media; DAPI, 4',6-diamidino-2-phenylindole; N, normoxia; $\mathrm{H}$, hypoxia; $\mathrm{Co}$, coculture; MHC, myosin heavy chain.

lymphoid enhancer binding factor 1 (Lef1), transcription factor 7 (Tcf7), cyclin D1 (Ccnd1) and cyclin A2 (Ccna2). After hDPSC-CM treatment, the expression of target genes was restored under hypoxic conditions (Fig. 5D-G). Furthermore, due to the possible involvement of the Wnt/ $\beta$-catenin pathway in the therapeutic effect of hDPSC-CM, the protein levels of Wnt ligands that mediate Wnt signaling activation in $\mathrm{C} 2 \mathrm{C} 12$ myoblasts were analyzed. These ligands included Wnt1, Wnt 4 and Wnt7a. It was observed that Wnt1 was decreased by hypoxia and then recovered after hDPSC-CM treatment, whereas there was no statistically significant difference in Wnt 4 and Wnt7a (Fig. 5H-K). The present results suggested that hDPSC-CM alleviated $\mathrm{C} 2 \mathrm{C} 12$ myoblast injury at least partly through activation of Wnt $1 / \beta$-catenin signaling. 
A

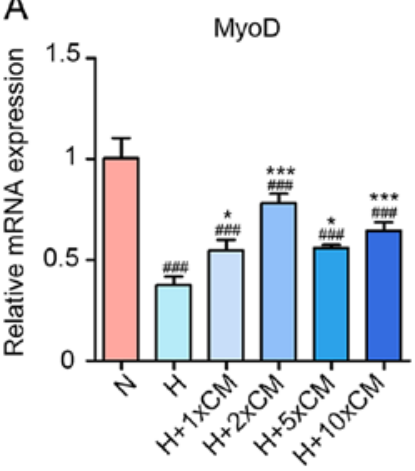

B

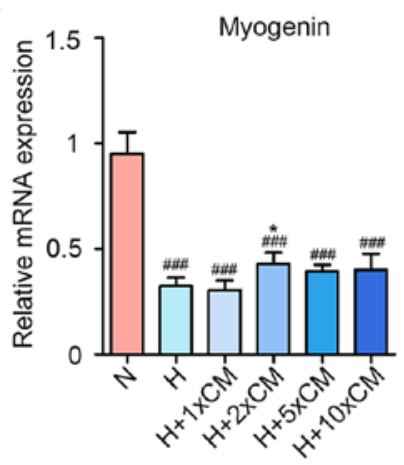

C

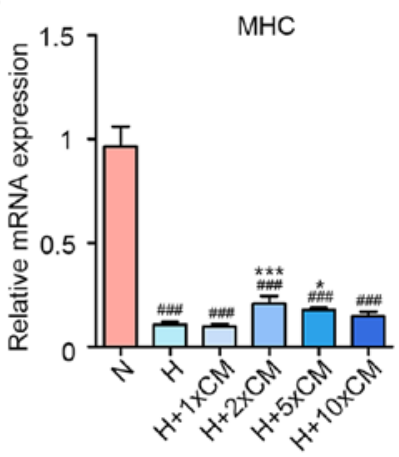

D

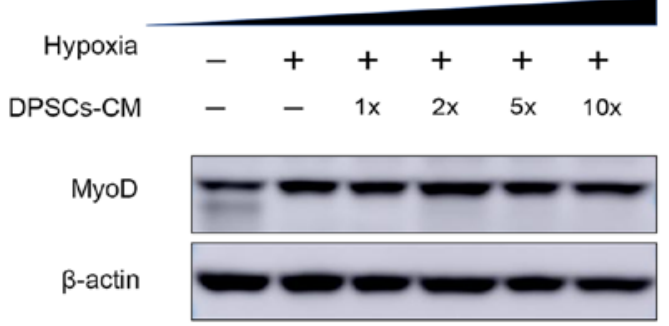

E

$\begin{array}{cccccccc}\text { Hypoxia } & - & + & + & + & + & + \\ \text { DPSCs-CM } & - & - & 1 \times & 2 x & 5 x & 10 x\end{array}$

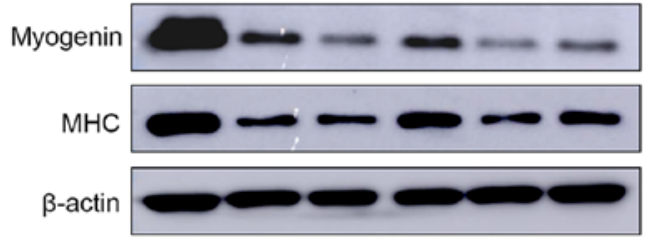

$\mathrm{H}$

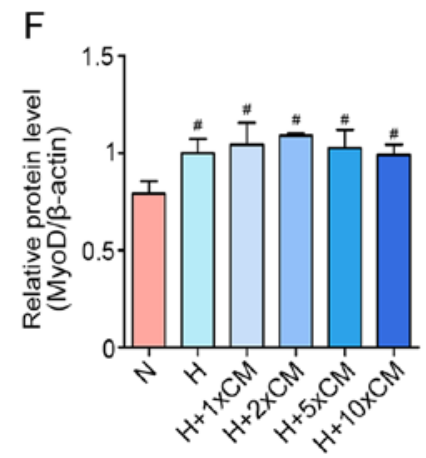

G

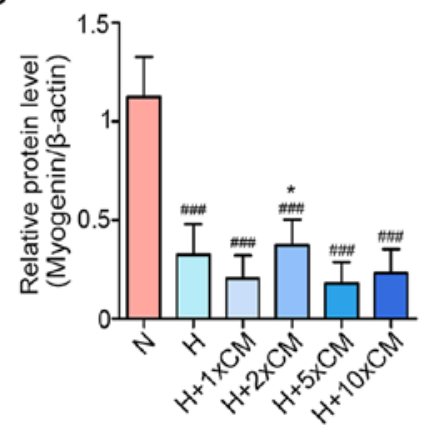

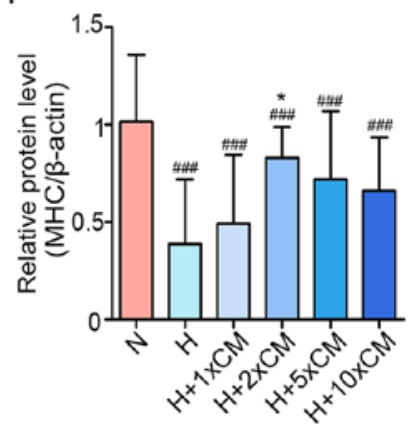

Figure 4. Appropriate concentration of hDPSC-CM improves the inhibition of myogenic differentiation. mRNA expression of (A) MyoD, (B) myogenin and (C) MHC. Protein levels of (D) MyoD, (E) myogenin and MHC during the differentiation process. Semiquantitative analysis of the expression ratios of (F) MyoD/ $\beta$-actin, (G) myogenin $/ \beta$-actin and (H) MHC $\beta$-actin. ${ }^{\#} \mathrm{P}<0.05$ and ${ }^{\# \# \#} \mathrm{P}<0.001$ vs. $\mathrm{N},{ }^{*} \mathrm{P}<0.05$ and ${ }^{* * *} \mathrm{P}<0.001$ vs. H. hDPSCs, human dental pulp stem cells; CM, conditioned media; DAPI, 4',6-diamidino-2-phenylindole; N, normoxia; H, hypoxia; MHC, myosin heavy chain.

The protective effect of hDPSC-CM is blocked by inhibition of Wnt/ $\beta$-catenin signaling. To further support the present results on the protective role of the Wnt/ $\beta$-catenin pathway in hDPSC-CM, XAV939 $(20 \mu \mathrm{M})$ was used a specific inhibitor of $\mathrm{Wnt} / \beta$-catenin that promotes the phosphorylation and degradation of $\beta$-catenin. The results revealed that XAV939 induced a decrease in both the differentiation indices and the Ki-67-positive rate compared with the $\mathrm{H}+\mathrm{CM}$ group (Fig. 6A-D). Moreover, the inhibitor XAV939 induced a reduction in the expression of myogenin and MHC compared with the $\mathrm{H}+\mathrm{CM}$ group (Fig. 6E and $\mathrm{F}$ ).

\section{Discussion}

The present study revealed that hDPSCs attenuated hypoxia-induced myoblast injury by improving viability and myogenic differentiation. It was demonstrated that hDPSCs activated the Wnt1/GSK-3 $\beta / \beta$-catenin signaling pathway by paracrine factors, which was at least partly responsible for these protective effects.
Previous studies have demonstrated pathological hypoxia-induced skeletal muscle myoblast injury, including the inhibition of viability and differentiation (43-45). Regarding viability, $\mathrm{CoCl}_{2}$ produced changes typical of cell death, such as characteristic cell extension, increased volume, chromatin condensation and G2/M phase cell cycle arrest, ultimately leading to reduced proliferation (13). Regarding myogenic differentiation, hypoxia, by degrading early and intermediate markers, such as MyoD and myogenin, prevented terminal differentiation (46). In the present study, following exposure to hypoxia, myoblasts exhibited a decrease in viability, arrest at the G2/M phase and inhibition of myogenin and MHC expression, which was in agreement with the aforementioned reports on skeletal muscle hypoxic injury.

MSCs and their derivatives are known to positively affect skeletal myogenesis and repair injury. In particular, fibroblast growth factor, hepatocyte growth factor, insulin-like growth factor, vascular endothelial growth factor and members of the Wnt family are involved in differentiation $(29,47,48)$. Therefore, the indirect coculture system was first adopted. Upon observing 
A

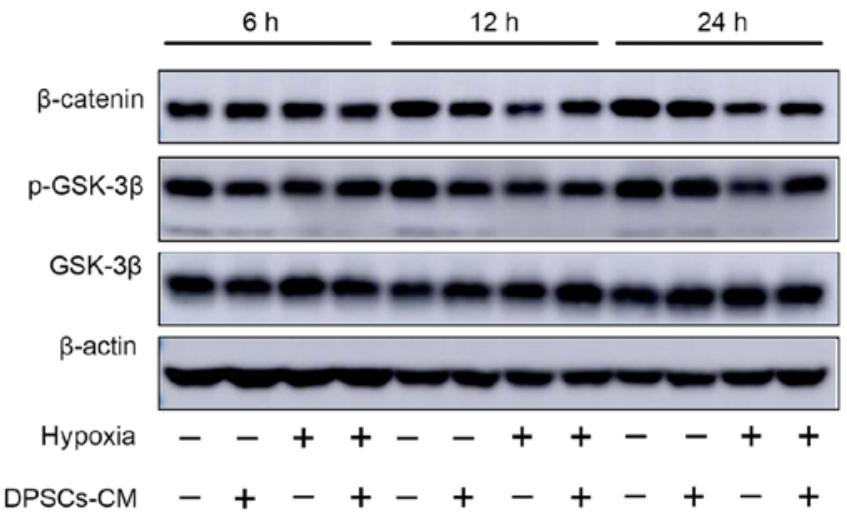

B

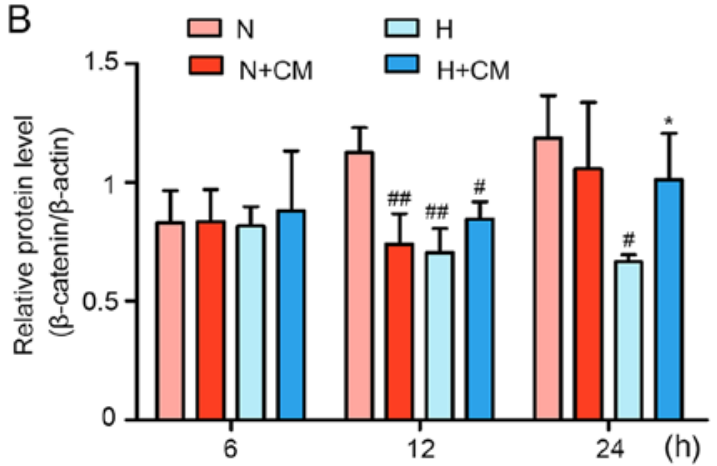

D

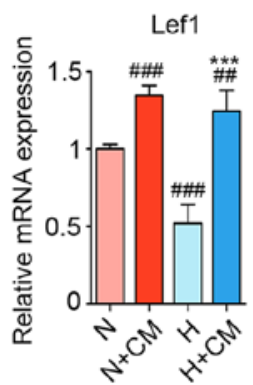

$\mathrm{H}$

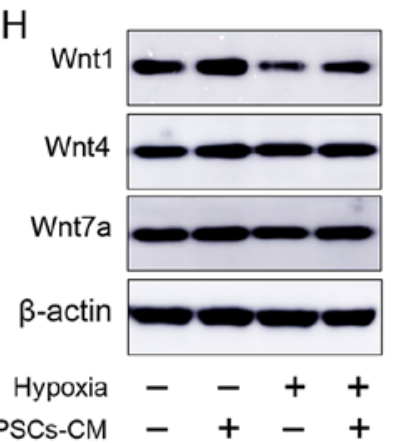

E

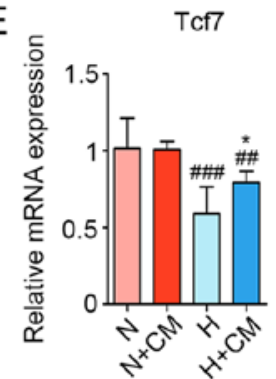

I

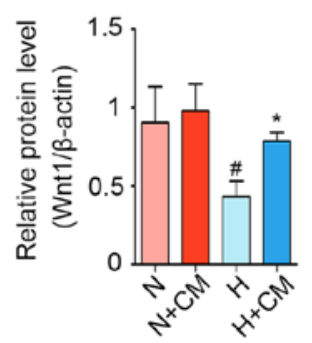

C

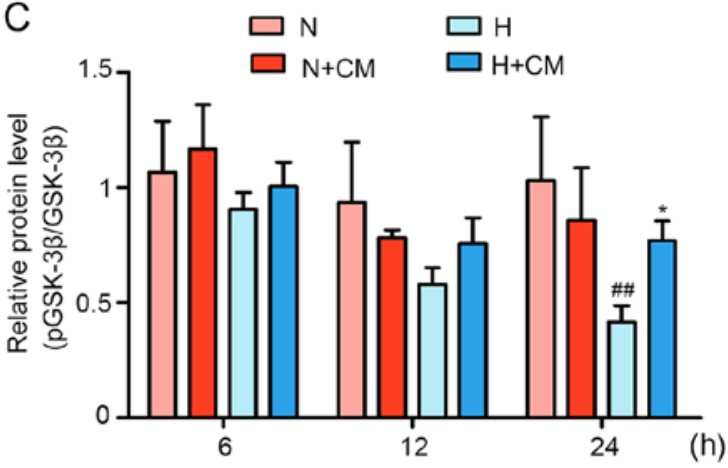

$\mathrm{F}$

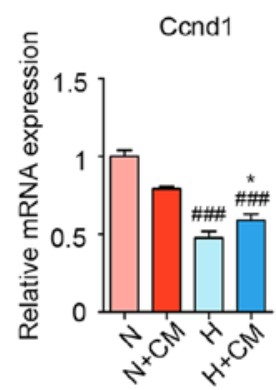

$J$

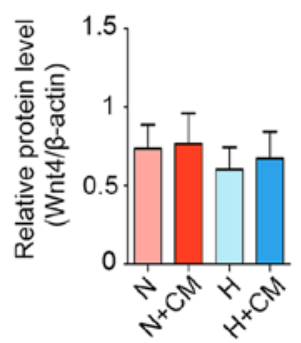

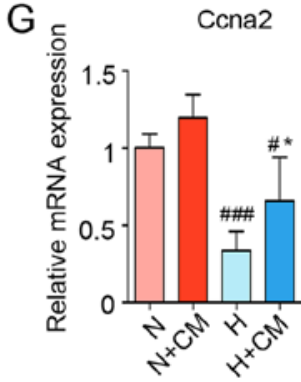

$\mathrm{K}$

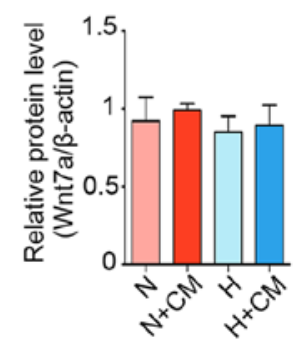

Figure 5. Wnt/ $\beta$-catenin signaling pathway is involved in hypoxia-induced $\mathrm{C} 2 \mathrm{C} 12$ myoblast injury and is activated by hDPSC-CM. (A) Expression of $\beta$-catenin, p-GSK-3 $\beta$ (S9) and total GSK-3 $\beta$ was detected using western blotting for 6, 12 and $24 \mathrm{~h}$. Semiquantitative analysis of the expression ratios of (B) $\beta$-catenin/ $\beta$-actin and (C) p-GSK-3 $\beta /$ GSK-3 $\beta$. The levels of the downstream effectors of $\beta$-catenin-related mRNAs, including (D) Lef1, (E) Tcf7, (F) Ccnd1 and $(\mathrm{G})$ Ccna2, were assessed using quantitative PCR. (H) Expression of Wnt signaling ligands, including Wnt1, Wnt4 and Wnt7a. Semiquantitative analysis of the expression ratio of (I) Wnt1/ $\beta$-actin, (J) Wnt $4 / \beta$-actin and (K) Wnt7a/ $\beta$-actin. ${ }^{\#} \mathrm{P}<0.05,{ }^{\# \#} \mathrm{P}<0.01$ and ${ }^{\# \# \# "} \mathrm{P}<0.001$ vs. $\mathrm{N},{ }^{*} \mathrm{P}<0.05$ and ${ }^{* * *} \mathrm{P}<0.001$ vs. $\mathrm{H}$. hDPSCs, human dental pulp stem cells; CM, conditioned media; p-GSK, phosphorylated-glycogen synthase kinase; Lef1, lymphoid enhancer binding factor 1; Tcf7, transcription factor 7; Ccnd1, cyclin D1; Ccna2, cyclin A2; N, normoxia; H, hypoxia.

a beneficial effect, it was hypothesized that these secretions were present in the $\mathrm{CM}$, and the results were then verified with hDPSC-CM. In previous applications of MSC-CM, however, most studies (49-52) did not compare the different concentrations of CM. Nagata et al (53) demonstrated that MSC-CM enhanced tissue regeneration and repair, depending on the concentration ratio of CM. However, different cells and tissues may have different sensitivities to different CM concentrations. In the present study, it was demonstrated that different hDPSC-CM concentrations produced different effects. In the process of myoblast proliferation, an $\sim 5$-fold concentration of $\mathrm{CM}$ is considered to have a significant effect; however, such 

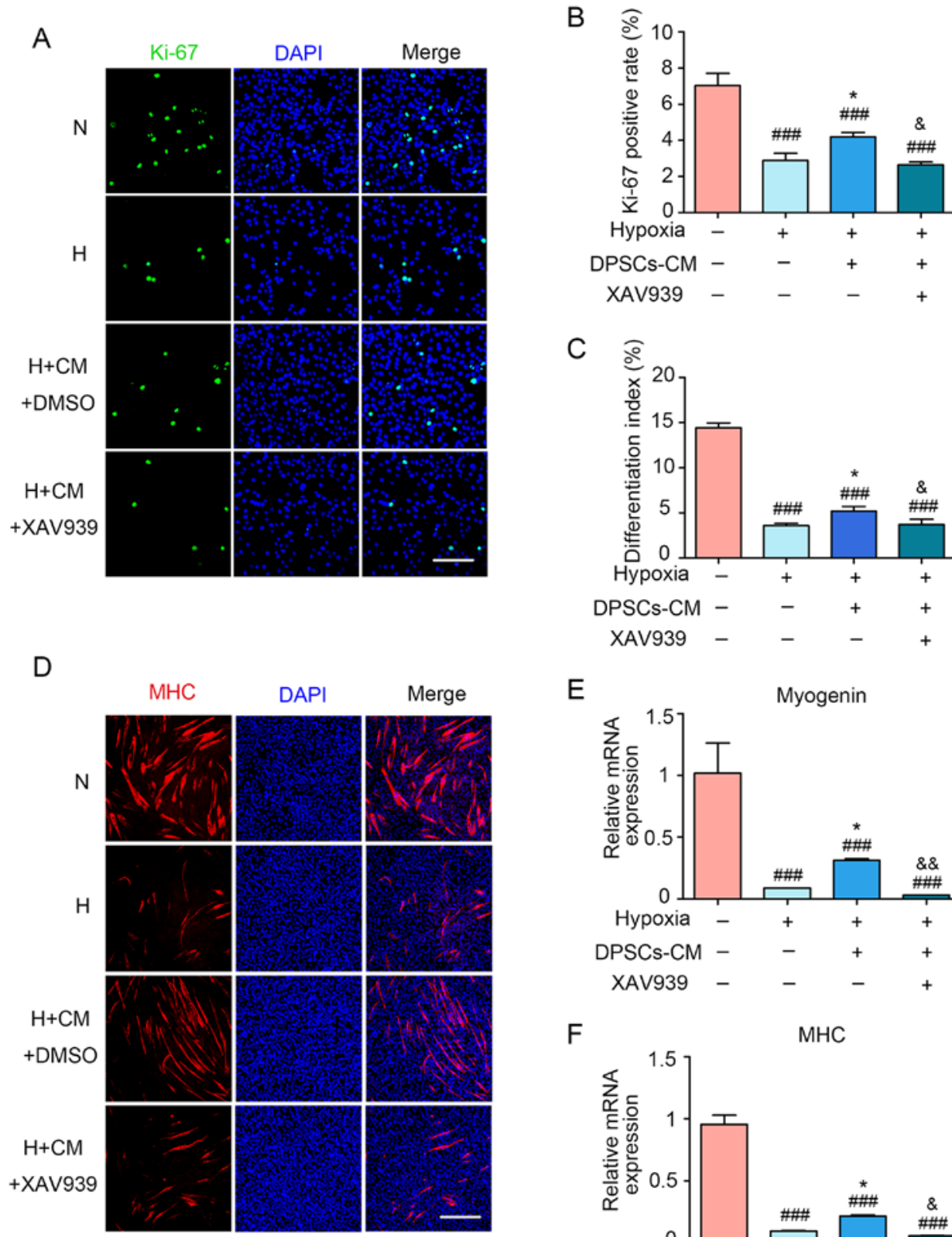

C

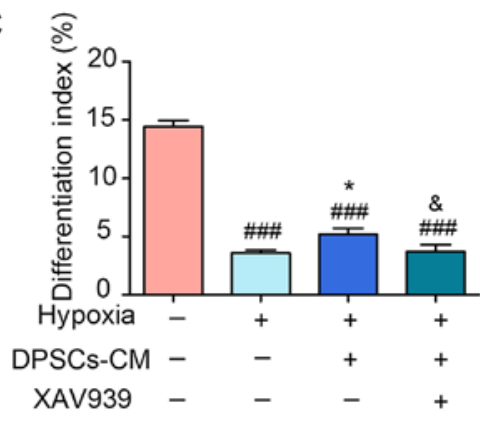

$\mathrm{E}$

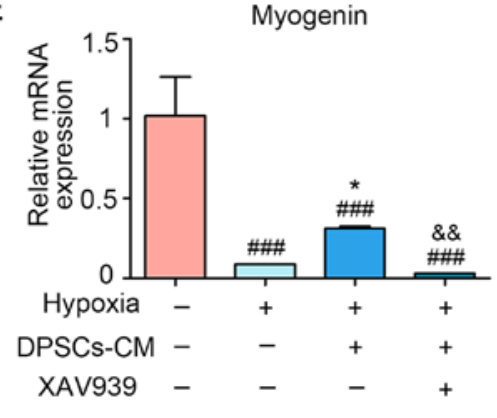

$\mathrm{F}$

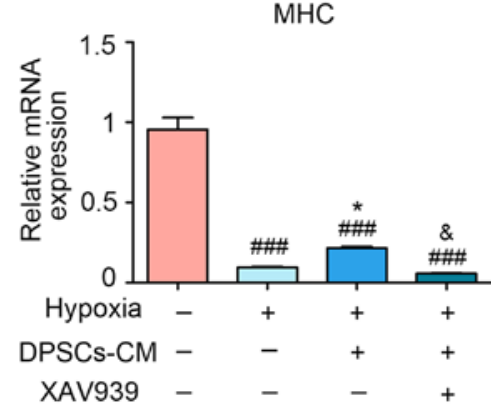

Figure 6. The protective effect of hDPSC-CM was blocked by using XAV939. (A) Cell proliferation was assessed through Ki-67 immunofluorescence staining. Scale bar, $100 \mu \mathrm{m}$. (B) Statistical analysis of the Ki-67-positive rate (\%). (C) The differentiation index was presented as the ratio between MHC-positive nuclei and the total number of nuclei. (D) Two days after hypoxia treatment, the formation of myotubes and cell nuclei was assessed via immunofluorescence staining with MHC (red) and DAPI (blue), respectively. Scale bar, $200 \mu \mathrm{m}$. The mRNA expression of (E) myogenin and (F) MHC was detected using quantitative PCR. ${ }^{\# \# \#} \mathrm{P}<0.001$ vs. $\mathrm{N},{ }^{*} \mathrm{P}<0.05$ vs. $\mathrm{H} .{ }^{\circledR} \mathrm{P}<0.05$ and ${ }^{\& \&} \mathrm{P}<0.01$ vs. H + CM. hDPSCs, human dental pulp stem cells; CM, conditioned media; DAPI, 4',6-diamidino-2-phenylindole; N, normoxia; H, hypoxia; MHC, myosin heavy chain.

a high concentration does not appear to be required during myoblast differentiation. In the present experiment, a protective effect was achieved using only an $\sim 2$-fold concentration during differentiation. This difference was considered to be caused by the differing demand for paracrine substances during the repair processes of proliferation and differentiation. Convincing evidence was presented herein that hDPSCs exert beneficial effects on myoblast hypoxic injury. However, there were several limitations to the present study. Primary DPSCs and their $\mathrm{CM}$ were derived from humans, while the $\mathrm{C} 2 \mathrm{C} 12$ myoblasts were from murine lines. Therefore, interactions between the two cells may be affected by structural differences of cytokines and proteins due to the different species. Although numerous soluble factors from humans and mice may interact, it is not true for all of them and the level of responsiveness may not be equal to that to cytokines from the same species. In the present study, $\mathrm{C} 2 \mathrm{C} 12$ myoblasts cocultured with human DPSCs achieved good cellular growth under normoxia, and even better under hypoxia, when compared with the $\mathrm{C} 2 \mathrm{C} 12$ alone groups. The interactions between the two types of cells appeared to be positive. However, the protective effect may be compromised. Additionally, the present 


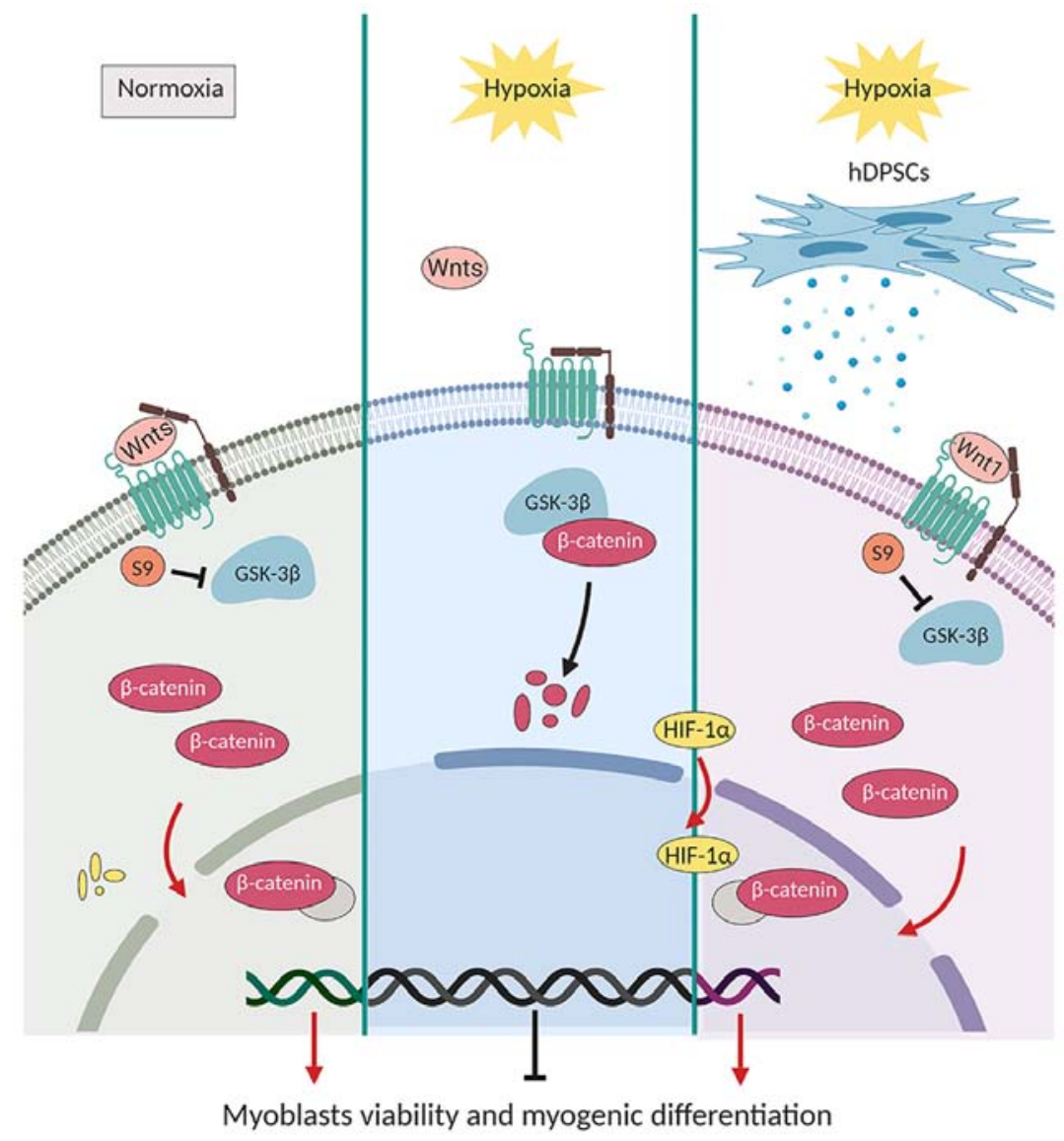

Figure 7. Schematic representation of the mechanisms underlying the secretome of hDPSCs in protecting C2C12 myoblasts against hypoxia-induced injury. Left: Under normoxic conditions, Wnt ligands are bound to receptors on the cell membrane, followed by the inactivation of GSK-3 $\beta$ after phosphorylation at S9 and $\beta$-catenin gradually accumulates and is transferred into the nucleus to promote the transcription of downstream target genes. Middle: Under hypoxic conditions, the relevant Wnt ligands do not bind to the receptor and $\beta$-catenin is phosphorylated to degrade after binding GSK-3 $\beta$, thereby inhibiting cell proliferation and myogenic differentiation. Right: The secretome of the hDPSC-activated Wnt1/GSK-3 $\beta / \beta$-catenin signaling pathway is at least partly responsible for these protective effects under hypoxia. The hDPSC secretome can attenuate hypoxia-induced myoblast injury by alleviating the inhibition of viability and promoting myogenic differentiation. GSK, glycogen synthase kinase; hDPSCs, human dental pulp stem cells; HIF, hypoxia inducible factor.

study was unable to mimic the dynamic changes of real tissue hypoxia. Thus, further studies are warranted to investigate the effect of hDPSCs on human primary skeletal myoblasts in hypoxia-related diseases.

The findings of the present study provide theoretical support for the exploration of the repair of hypoxic damage to myoblasts by hDPSCs; however, a deeper understanding of the underlying mechanism of these findings requires further investigation. Wnt signaling also plays a crucial role in the regulation of myogenic differentiation, as Wnt is induced and promotes myoblast differentiation and myotube fusion (54). Wnt ligands bind to low-density lipoprotein-related protein/frizzled complexes on the cell membrane and after phosphorylation, inactivation of GSK-3 $\beta$ leads to stabilization of $\beta$-catenin. This gradually accumulates and is transferred into the nucleus to promote transcription of downstream specific target genes (such as Lef1 and Ccnd1), or directly activates MyoD and upregulates myogenic regulatory factor coactivators (42). The Wnt signaling pathway is weakly activated in mature skeletal muscle. However, after injury, satellite cells are activated in the skeletal muscle, where numerous Wnt ligands (such as Wnt1, Wnt3a, Wnt4 and Wnt7a/b) are expressed and secreted (37). Moreover, Leroux et al (48) reported that MSCs, via the Wnt4 pathway, improved skeletal muscle fiber regeneration following ischemic injury. Other studies have also demonstrated activation of the Wnt pathway by MSCs (55-57). The present study found that, in the presence of hDPSC-CM, the levels of $\mathrm{Wnt} / \beta$-catenin pathway-related proteins, including p-GSK-3 $\beta$ and $\beta$-catenin, were upregulated. Furthermore, the downstream target genes of Wnt/ $\beta$-catenin, including Lef1, Tcf7, Ccnd1 and Ccna2, were inhibited by hypoxia, whereas their expression levels were restored after hDPSC-CM treatment. To confirm these data, in the presence of hDPSC-CM, myoblasts were cultured with $20 \mu \mathrm{M}$ of the Wnt/ $\beta$-catenin inhibitor XAV939 and the protective effects were blocked. These results suggest that the protective role of hDPSCs on $\mathrm{C} 2 \mathrm{C} 12$ hypoxia-induced injury requires the participation of the Wnt signaling pathway.

Under hypoxic conditions, the $\mathrm{Wnt} / \beta$-catenin pathway is directly or indirectly modulated. A previous study reported that HIF- $1 \alpha$ blocked the Wnt/ $\beta$-catenin signaling pathway by inhibiting hARD1-mediated $\beta$-catenin (58). Indeed, increased expression of HIF-1 $\alpha$ inhibits canonical Wnt signaling during skeletal muscle repair, as reflected by the increased target genes of $\beta$-catenin expression after silencing HIF-1 $\alpha$ (42). Thus, the present study hypothesized that the paracrine protective effect of hDPSCs through activation of the $\mathrm{Wnt} / \beta$-catenin pathway was related to the prevention of HIF-1 $\alpha$ accumulation. 
However, in the current study, hDPSC-CM did not decrease hypoxia-induced HIF-1 $\alpha$ stabilization.

During the various stages of skeletal muscle repair and regeneration, correct activation of the Wnt signaling pathways is crucial. Wnt 1 and Wnt4 mainly activate the canonical Wnt pathway (37). However, Wnt7a did not activate $\beta$-catenin in myoblasts or muscle myofibers. Indeed, by regulating the PCP pathway, Wnt7a signaling can be described as a non-canonical Wnt pathway (42). C2C12, in which the $\mathrm{Wnt} 1 / \beta$-catenin pathway was able to enhance myogenic differentiation, indicates one of the potential roles of canonical Wnt signaling in skeletal muscle (59). Consistent with reports mentioned above, the present study demonstrated that hDPSC-CM activated Wnt1 and $\beta$-catenin expression and regulated GSK-3 $\beta$ at S9, leading to its inactivation. Therefore, hDPSC-CM may restore the $\mathrm{Wnt} 1 / \beta$-catenin pathway in myoblasts to alleviate hypoxia-induced injury.

In summary, the findings of the present study suggest that hDPSCs may alleviate hypoxia-induced injury in $\mathrm{C} 2 \mathrm{C} 12$ myoblasts and the underlying mechanism may be associated with regulation of the Wnt $1 / \beta$-catenin signaling pathway (Fig. 7). The next step would be to assess which paracrine factors of hDPSCs are effective in repairing injured myoblasts, and determine whether another mechanism could be involved in vitro or in an animal model.

\section{Acknowledgements}

Not applicable.

\section{Funding}

The present study was funded by the National Natural Science Foundation of China (grant nos. 81771109 and 81600897); the General Program Shanghai Municipal Health and Family Planning Commission (grant nos. 201640023 and 201740091; and the Natural Science Foundation of Shanghai (grant no. 19ZR1445400).

\section{Availability of data and materials}

The datasets used and/or analyzed during the present study are available from the corresponding author on reasonable request.

\section{Authors' contributions}

WZ: Conception and design, data analysis and interpretation, manuscript writing and figure editing. LY: Experiment operation, data collection, analysis and interpretation. XH and YLu: Financial support, data analysis and interpretation. JP, JD, LZ, WH and SL: Provision of study materials, collection and assembly of data. YLiu and QL: Conception and design, financial support, data analysis and interpretation. WZ and LY contributed equally. All the authors have read and approved the final version of the manuscript.

\section{Ethics approval and consent to participate}

The protocols were approved by the Shanghai Stomatological Hospital Ethics Association (Shanghai, China). Written informed consent was obtained from all participants.

\section{Patient consent for publication}

Not applicable.

\section{Competing interests}

The authors declare that they have no competing interests.

\section{References}

1. Koh MY and Powis G: Passing the baton: The HIF switch. Trends Biochem Sci 37: 364-372, 2012.

2. Chaillou T: Skeletal muscle fiber type in hypoxia: Adaptation to high-altitude exposure and under conditions of pathological hypoxia. Front Physiol 9: 1450, 2018.

3. Adams V, Linke A and Winzer E: Skeletal muscle alterations in HFrEF vs. HFpEF. Current Heart Failure Reports 14: 489-497, 2017.

4. Gea J, Agusti A and Roca J: Pathophysiology of muscle dysfunction in COPD. J Appl Physiol (1985) 114: 1222-1234, 2013.

5. Putti R, Migliaccio V, Sica R and Lionetti L: Skeletal muscle mitochondrial bioenergetics and morphology in high fat diet induced obesity and insulin resistance: Focus on dietary fat source. Front Physiol 6: 426, 2016.

6. Lu Y, Liu Y and Li Y: Comparison of natural estrogens and synthetic derivative on genioglossus function and estrogen receptors expression in rats with chronic intermittent hypoxia. J Steroid Biochem Mol Biol 140: 71-79, 2014.

7. Williams R, Lemaire P, Lewis P, McDonald FB, Lucking E, Hogan S, Sheehan D, Healy V and O'Halloran KD: Chronic intermittent hypoxia increases rat sternohyoid muscle NADPH oxidase expression with attendant modest oxidative stress. Front Physiol 6: 15, 2015.

8. Beaudry M, Hidalgo M, Launay $\mathrm{T}$, Bello V and Darribère $\mathrm{T}$ : Regulation of myogenesis by environmental hypoxia. J Cell Sci 129: 2887-2896, 2016.

9. Chaillou T, Koulmann N, Meunier A, Chapot R, Serrurier B, Beaudry $M$ and Bigard $X$ : Effect of hypoxia exposure on the recovery of skeletal muscle phenotype during regeneration. Mol Cell Biochem 390: 31-40, 2014.

10. Favier FB, Britto FA, Freyssenet DG, Bigard XA and Benoit H: HIF-1-driven skeletal muscle adaptations to chronic hypoxia: Molecular insights into muscle physiology. Cell Mol Life Sci 72: 4681-4696, 2015

11. Quadrilatero J, Alway SE and Dupont-Versteegden EE: Skeletal muscle apoptotic response to physical activity: Potential mechanisms for protection. Appl Physiol Nutr Metab 36: 608-617, 2011.

12. L'honoré A, Commère PH, Ouimette JF, Montarras D, Drouin J and Buckingham M: Redox regulation by Pitx 2 and Pitx 3 is critical for fetal myogenesis. Dev Cell 39: 756, 2016.

13. Muñoz-Sánchez J and Chánez-Cárdenas ME: The use of cobalt chloride as a chemical hypoxia model. J Appl Toxicol 39: 556-570, 2019.

14. Hayot M, Rodriguez J, Vernus B, Carnac G, Jean E, Allen D, Goret L, Obert P, Candau R and Bonnieu A: Myostatin up-regulation is associated with the skeletal muscle response to hypoxic stimuli. Mol Cell Endocrinol 332: 38-47, 2011.

15. Chen R, Xu J, She Y, Jiang T, Zhou S, Shi H and Li C: Necrostatin-1 protects $\mathrm{C} 2 \mathrm{C} 12$ myotubes from $\mathrm{CoCl} 2$-induced hypoxia. Int J Mol Med 41: 2565-2572, 2018.

16. Baskaran R, Kalaiselvi P, Huang CY and Padma VV: Neferine, a bisbenzylisoquinoline alkaloid, offers protection against cobalt chloride-mediated hypoxia-induced oxidative stress in muscle cells. Integr Med Res 4: 231-241, 2015.

17. Chen R, Jiang T, She Y, Xu J, Li C, Zhou S, Shen H, Shi H and Liu S: Effects of cobalt chloride, a hypoxia-mimetic agent, on autophagy and atrophy in skeletal C2C12 myotubes. Biomed Res Int 2017: 7097580, 2017.

18. Rovetta F, Stacchiotti A, Faggi F, Catalani S, Apostoli P, Fanzani A and Aleo MF: Cobalt triggers necrotic cell death and atrophy in skeletal C2C12 myotubes. Toxicol Appl Pharmacol 271: 196-205, 2013.

19. Jaitovich A and Barreiro E: Skeletal muscle dysfunction in chronic obstructive pulmonary disease. What we know and can do for our patients. Am J Respir Crit Care Med 198: 175-186, 2018.

20. Hirai DM, Musch TI and Poole DC: Exercise training in chronic heart failure: Improving skeletal muscle O2 transport and utilization. Am J Physiol Heart Circ Physiol 309: H1419-H1439, 2015. 
21. Guimarães KC, Drager LF, Genta PR, Marcondes BF and Lorenzi-Filho G: Effects of oropharyngeal exercises on patients with moderate obstructive sleep apnea syndrome. Am J Respir Crit Care Med 179: 962-966, 2009.

22. Chaudhary P, Sharma YK, Sharma S, Singh SN and Suryakumar G: High altitude mediated skeletal muscle atrophy: Protective role of curcumin. Biochimie 156: 138-147, 2019.

23. Kerkis I, Ambrosio CE, Kerkis A, Martins DS, Zucconi E, Fonseca SA, Cabral RM, Maranduba CM, Gaiad TP, Morini AC, et al: Early transplantation of human immature dental pulp stem cells from baby teeth to golden retriever muscular dystrophy (GRMD) dogs: Local or systemic? J Transl Med 6: 35, 2008.

24. Nakatsuka R, Nozaki T, Uemura Y, Matsuoka Y, Sasaki Y, Shinohara M, Ohura K and Sonoda Y: 5-Aza-2'-deoxycytidine treatment induces skeletal myogenic differentiation of mouse dental pulp stem cells. Arch Oral Biol 55: 350-357, 2010.

25. Spath L, Rotilio V, Alessandrini M, Gambara G, De Angelis L, Mancini M, Mitsiadis TA, Vivarelli E, Naro F, Filippini A and Papaccio G: Explant-derived human dental pulp stem cells enhance differentiation and proliferation potentials. J Cell Mol Med 14: 1635-1644, 2010.

26. Kichenbrand C, Velot E, Menu P and Moby V: Dental pulp stem cell-derived conditioned medium: An attractive alternative for regenerative therapy. Tissue Eng Part B Rev 25: 78-88, 2019.

27. Madrigal M, Rao KS and Riordan NH: A review of therapeutic effects of mesenchymal stem cell secretions and induction of secretory modification by different culture methods. J Trans Med 12: 260, 2014.

28. Assoni A, Coatti G, Valadares MC, Beccari M, Gomes J, Pelatti M, Mitne-Neto M, Carvalho VM and Zatz M: Different donors mesenchymal stromal cells secretomes reveal heterogeneous profile of relevance for therapeutic use. Stem Cells Dev 26: 206-214, 2017.

29. Liang X, Ding Y, Zhang Y, Tse HF and Lian Q: Paracrine mechanisms of mesenchymal stem cell-based therapy: Current status and perspectives. Cell Transplant 23: 1045-1059, 2014

30. Park CM, Kim MJ, Kim SM, Park JH, Kim ZH and Choi YS Umbilical cord mesenchymal stem cell-conditioned media prevent muscle atrophy by suppressing muscle atrophy-related proteins and ROS generation. In Vitro Cell Dev Biol Anim 52: 68-76, 2016.

31. Kim MJ, Kim ZH, Kim SM and Choi YS: Conditioned medium derived from umbilical cord mesenchymal stem cells regenerates atrophied muscles. Tissue Cell 48: 533-543, 2016.

32. Cho KA, Park M, Kim YH, Woo SY and Ryu KH: Conditioned media from human palatine tonsil mesenchymal stem cells regulates the interaction between myotubes and fibroblasts by IL-1Ra activity. J Cell Mol Med 21: 130-141, 2017.

33. Mouse Genome Sequencing Consortium, Waterston RH, Lindblad-Toh K, Birney E, Rogers J, Abril JF, Agarwal P, Agarwala R, Ainscough R, Alexandersson M, et al: Initial sequencing and comparative analysis of the mouse genome. Nature 420: 520-562, 2002

34. Naskar S, Kumaran V, Markandeya YS, Mehta B and Basu B: Neurogenesis-on-Chip: Electric field modulated transdifferentiation of human mesenchymal stem cell and mouse muscle precursor cell coculture. Biomaterials 226: 119522, 2020.

35. Zhao Y, Li N, Li Z, Zhang D, Chen L, Yao Z and Niu W: Conditioned medium from contracting skeletal muscle cells reverses insulin resistance and dysfunction of endothelial cells. Metabolism 82: 36-46, 2018

36. Kwon S, Ki SM, Park SE, Kim MJ, Hyung B, Lee NK, Shim S, Choi BO, Na DL, Lee JE and Chang JW: Anti-apoptotic effects of human Wharton's Jelly-derived mesenchymal stem cells on skeletal muscle cells mediated via secretion of XCL1. Mol Ther 24: 1550-1560, 2016.

37. Girardi $F$ and Le Grand F: Wnt signaling in skeletal muscle development and regeneration. Prog Mol Biol Transl Sci 153 $157-179,2018$.

38. Livak KJ and Schmittgen TD: Analysis of relative gene expression data using real-time quantitative PCR and the 2(-Delta Delta C(T)) method. Methods 25: 402-408, 2001

39. Comai G and Tajbakhsh S: Molecular and cellular regulation of skeletal myogenesis. Curr Top Dev Biol 110: 1-73, 2014.

40. Cho OH,Mallappa C, Hernández-Hernández JM, Rivera-Pérez JA and Imbalzano AN: Contrasting roles for MyoD in organizing myogenic promoter structures during embryonic skeletal muscle development. Dev Dyn 244: 43-55, 2015.

41. Zhu X and Lu X: MiR-423-5p inhibition alleviates cardiomyocyte apoptosis and mitochondrial dysfunction caused by hypoxia/reoxygenation through activation of the wnt/ $\beta$-catenin signaling pathway via targeting MYBL2. J Cell Physiol 234: 22034-22043, 2019.
42. Majmundar AJ, Lee DS, Skuli N, Mesquita RC, Kim MN, Yodh AG, Nguyen-McCarty M, Li B and Simon MC: HIF modulation of Wnt signaling regulates skeletal myogenesis in vivo. Development 142: 2405-2412, 2015.

43. Drouin G, Couture V, Lauzon MA, Balg F, Faucheux N and Grenier G: Muscle injury-induced hypoxia alters the proliferation and differentiation potentials of muscle resident stromal cells. Skelet Muscle 9: 18, 2019.

44. Rahar B, Chawla S, Pandey S, Bhatt AN and Saxena S: Sphingosine-1-phosphate pretreatment amends hypoxia-induced metabolic dysfunction and impairment of myogenic potential in differentiating $\mathrm{C} 2 \mathrm{C} 12$ myoblasts by stimulating viability, calcium homeostasis and energy generation. J Physiol Sci 68: 137-151, 2018.

45. Pagé M, Maheux C, Langlois A, Brassard J, Bernatchez É, Martineau S,Henry C,Beaulieu MJ,Bossé Y,Morissette MC, et al: $\mathrm{CD} 34$ regulates the skeletal muscle response to hypoxia. J Muscle Res Cell Motil 40: 309-318, 2019.

46. Di Carlo A, De Mori R, Martelli F, Pompilio G, Capogrossi MC and Germani A: Hypoxia inhibits myogenic differentiation through accelerated MyoD degradation. J Biol Chem 279: 16332-16338, 2004.

47. Aziz A, Sebastian S and Dilworth FJ: The origin and fate of muscle satellite cells. Stem Cell Rev 8: 609-622, 2012.

48. Leroux L, Descamps B, Tojais NF, Séguy B, Oses P Moreau C, Daret D, Ivanovic Z, Boiron JM, Lamazière JM, et al: Hypoxia preconditioned mesenchymal stem cells improve vascular and skeletal muscle fiber regeneration after ischemia through a Wnt4-dependent pathway. Mol Ther 18: 1545-1552, 2010.

49. Gao T, Yu Y, Cong Q, Wang Y, Sun M, Yao L, Xu C and Jiang W: Human mesenchymal stem cells in the tumour microenvironment promote ovarian cancer progression: The role of platelet-activating factor. BMC Cancer 18: 999, 2018.

50. Chen B, Ni Y, Liu J, Zhang Y and Yan F: Bone marrow-derived mesenchymal stem cells exert diverse effects on different macrophage subsets. Stem Cells Int 2018: 8348121, 2018.

51. Azhdari Tafti Z, Mahmoodi M, Hajizadeh MR, Ezzatizadeh V, Baharvand $\mathrm{H}$, Vosough $\mathrm{M}$ and Piryaei A: Conditioned media derived from human adipose tissue mesenchymal stromal cells improves primary hepatocyte maintenance. Cell J 20: 377-387, 2018.

52. Periasamy R, Surbek DV and Schoeberlein A: In vitro-microenvironment directs preconditioning of human chorion derived MSC promoting differentiation of OPC-like cells. Tissue Cell 52: 65-70, 2018

53. Nagata M, Iwasaki K, Akazawa K, Komaki M, Yokoyama N, Izumi Y and Morita I: Conditioned medium from periodontal ligament stem cells enhances periodontal regeneration. Tissue Eng Part A 23: 367-377, 2017.

54. von Maltzahn J, Chang NC, Bentzinger CF and Rudnicki MA: Wnt signaling in myogenesis. Trends Cell Biol 22: 602-609, 2012

55. Wang L, Qing L, Liu H, Liu N, Qiao J, Cui C, He T, Zhao R, Liu F, Yan F, et al: Mesenchymal stromal cells ameliorate oxidative stress-induced islet endothelium apoptosis and functional impairment via Wnt4- $\beta$-catenin signaling. Stem Cell Res Ther 8 : $188,2017$.

56. Guo X, Gu X, Hareshwaree S, Rong X, Li L and Chu M: Induced pluripotent stem cell-conditional medium inhibits $\mathrm{H} 9 \mathrm{C} 2$ cardiomyocytes apoptosis via autophagy flux and $\mathrm{Wnt} / \beta$-catenin pathway. J Cell Mol Med 23: 4358-4374, 2019.

57. Guo X, Chen Y, Hong T, Chen X, Duan Y, Li C and Ge R: Induced pluripotent stem cell-derived conditional medium promotes Leydig cell anti-apoptosis and proliferation via autophagy and Wnt/ $\beta$-catenin pathway. J Cell Mol Med 22: 3614-3626, 2018.

58. Lim JH, Chun YS and Park JW: Hypoxia-inducible factor-1alpha obstructs a Wnt signaling pathway by inhibiting the hARD1-mediated activation of beta-catenin. Cancer Res 68: 5177-5184, 2008.

59. Rochat A, Fernandez A, Vandromme M, Molès JP, Bouschet T, Carnac $\mathrm{G}$ and Lamb NJ: Insulin and wnt1 pathways cooperate to induce reserve cell activation in differentiation and myotube hypertrophy. Mol Biol Cell 15: 4544-4555, 2004.

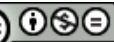

This work is licensed under a Creative Commons Attribution-NonCommercial-NoDerivatives 4.0 International (CC BY-NC-ND 4.0) License. 